\title{
Uncertainty Analysis of an Updated Dose Assessment for a U.S. Nuclear Test Site- Bikini Atoll
}

Kenneth T. Bogen

Cynthia L. Conrado

William L. Robison

November 1995

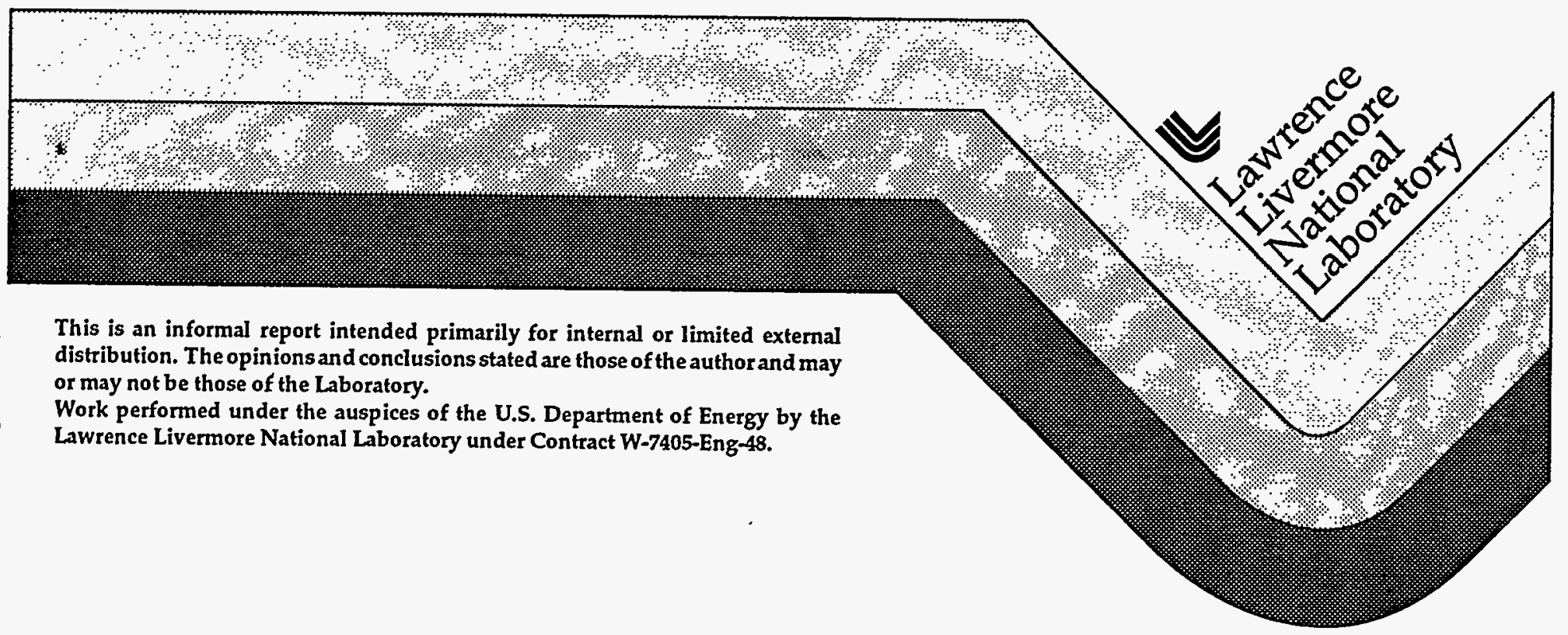




\section{DISCLAIMER}

This document was prepared as an account of work sponsored by an agency of the United States Government. Neither the United States Government nor the University of Califomia nor any of their employees, makes any warranty, express or implied, or assumes any legal liability or responsibility for the accuracy, completeness, or usefulness of any information, apparatus, product, or process disclosed, or represents that its use would not infringe privately own rights. Reference herein to any specific commercial products, process, or service by trade name, trademark, manufacturer, or otherwise, does not necessarily constitute or imply its endorsement, recommendation, or favoring by the United States Government or the University of California. The views and opinions of authors expressed herein do not necessarily state or reflect those of the United States Government or the University of California, and shall not be used for advertising or product endorsement purposes.

This report has been reproduced

directly from the best available copy.

Available to DOE and DOE contractors from the

Office of Scientific and Technical Information

P.O. Box 62, Oak Ridge, TN 37831

Prices available from (615) 576-8401, FIS 626-8401

Available to the public from the

National Technical Information Service

U.S. Department of Commerce

5285 Port Royal Rd.

Springfield, VA 22161 


\title{
Uncertainty Analysis for an Updated Dose Assessment for a U.S. Nuclear Test Site: Bikini Atoll
}

\author{
Kenneth T. Bogen \\ Cynthia L. Conrado \\ William L. Robison
}

Health \& Ecological Assessment Division

Environmental Programs Directorate

November 1995 


\section{Table of Contents}

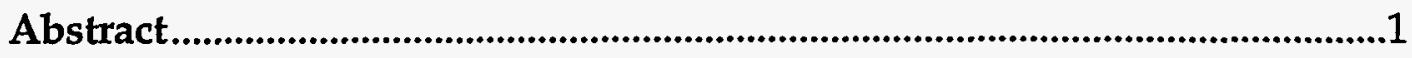

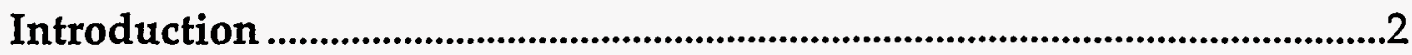

Table 1. 30-, 50- and 70-y integral effective dose estimates ......................3

Methods Used to Estimate Uncertainty and Interindividual

Variability in Bikini Doses and Corresponding Population Risk......4

Dose-model parameter distributions .............................................................6

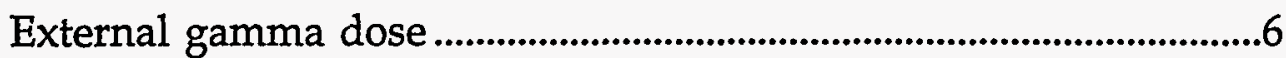

Metabolic factors for ${ }^{137} \mathrm{Cs}$.....................................................................6

Table 2. Parameters used in analysis of uncertainty and variability in estimated dose to hypothetical Bikini residents. ............................7

Metabolic factors for ${ }^{90} \mathrm{Sr}$.......................................................................8

Figure 1. Weighting function addressing fraction of ingested ${ }^{90} \mathrm{Sr}$ absorbed at age $t$.....................................................................................9

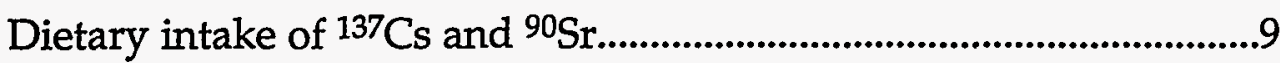

Figure 2. Interindividual variability in daily intake of ${ }^{137} \mathrm{Cs}$ per unit body weight based on survey data for 34 adult Ujelang females.

Table 3. Diet Model-Bikini Island for adults for ${ }^{137} \mathrm{Cs}$ Ingestion. $\mathrm{a}, \mathrm{b} . . . . .11$

Table 4. Diet Model-Bikini Island for adults for ${ }^{90} \mathrm{Sr}$ Ingestion. $. \mathrm{a}, \mathrm{b} . . . . . . .14$

Figure 3. Scatterplot of ${ }^{137} \mathrm{Cs}$ and ${ }^{90} \mathrm{Sr}$ concentrations in drinking-coconut meat from 70 different coconuts on

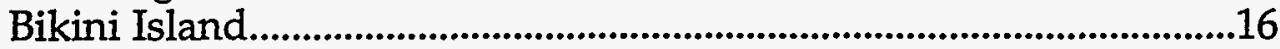

Population Risk .................................................................................................17

Estimated Uncertainty and Interindividual Variability in Bikini Doses, \& Corresponding Estimated Population Risk. .18

Table 5. Uncertainty and interindividual variability in estimated doses for hypothetical Bikini Island residents.

Figure 4. Distributions characterizing interindividual variability in expected 70-y effective integral dose and uncertainty in population-average 70-y effective integral dose, and corresponding Monte-Carlo sampling errors.

Figure 5. Distributions characterizing interindividual variability in the maximum value of expected 1-y effective integral doses, and corresponding Monte-Carlo sampling errors. 
Figure 6. Expected dose over time and 95\% confidence limits with respect to interindividual variability, and population-average dose over time and $95 \% \mathrm{CL}$ with respect to uncertainty.

Appendix

Figure A1. Expected population-average adult ${ }^{137} \mathrm{Cs}$ dose to potential Bikini Island residents as a function of postresettlement time starting in 1999: ICRP (1990) model vs. model used in this report.

Figure A2. Standard deviation (SD), denoted $\sigma_{\overline{X_{1 \beta}}}$ in Eq. (A9), as a function of the corresponding expected value (Expectation), denoted $\overline{\langle X \mid \beta\rangle}$ in Eq. (A8)...............................................................28

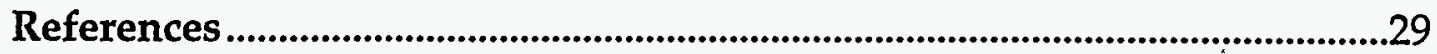




\begin{abstract}
A detailed analysis of uncertainty and interindividual variability in estimated doses was conducted for a rehabilitation scenario for Bikini Island at Bikini Atoll, in which the top $40 \mathrm{~cm}$ of soil would be removed in the housing and village area, and the rest of the island is treated with potassium fertilizer, prior to an assumed resettlement date of 1999. Predicted doses were considered for the following falloutrelated exposure pathways: ingested Cesium-137 and Strontium-90, external gamma exposure, and inhalation and ingestion of Americium-241 + Plutonium-239+240. Two dietary scenarios were considered: (1) imported foods are available (IA), and (2) imported foods are unavailable (only local foods are consumed) (IUA). Corresponding calculations of uncertainty in estimated population-average dose showed that after $\sim 5$ y of residence on Bikini, the upper and lower $95 \%$ confidence limits with respect to uncertainty in this dose are estimated to be approximately 3fold higher and lower than its population-average value, respectively (under both IA and IUA assumptions). Corresponding calculations of interindividual variability in the expected value of dose with respect to uncertainty showed that after $\sim 5 \mathrm{y}$ of residence on Bikini, the upper and lower $95 \%$ confidence limits with respect to interindividual variability in this dose are estimated to be approximately 2-fold higher and lower than its expected value, respectively (under both IA and IUA assumptions). For reference, the expected values of population-average dose at age 70 were estimated to be 1.6 and $5.2 \mathrm{cSv}$ under the IA and IUA dietary assumptions, respectively. Assuming that 200 Bikini resettlers would be exposed to local foods (under both IA and IUA assumptions), the maximum 1-y dose received by any Bikini resident is most likely to be approximately 2 and $8 \mathrm{mSv}$ under the IA and IUA assumptions, respectively. Under the most likely dietary scenario, involving access to imported foods, this analysis indicates that it is most likely that no additional cancer fatalities (above those normally expected) would arise from the increased radiation exposures considered.
\end{abstract}




\section{Introduction}

This report supplements an updated dose assessment for Bikini Island at Bikini Atoll (Robison et al., 1995), which addressed doses estimated under two resettlement options: (1) current conditions assuming no environmental remediation, and (2) resettlement after soil removal in the housing and village area, and potassium treatment of the rest of the island. The present detailed analysis of uncertainty and interindividual variability in estimated doses to potential Bikini resettlers focuses only on resettlement option (2), which assumes rehabilitation prior to resettlement.

The estimated maximum-annual and integral effective (whole-body-equivalent) doses for the rehabilitation scenario presented in Robison et al. (1995) were calculated using best estimates for each of the input parameters of the exposure and dosimetry models used in that report, including parameters reflecting: radionuclide concentrations in foods, biological removal rates, deposition of radionuclides in organs or the whole body, and external dose rates. These estimated doses were presented for two dietary scenarios (IA and IUA). The first dietary assumption used by Robison et al. (1995) was that imported foods will be available (IA) to Bikini residents and that $60 \%$ of the diet will be made up of these imported foods, with the remainder being derived from local sources. The alternative dietary assumption used by Robison et al. (1995) was that imported foods will be unavailable (IUA), that is, that only local foods will be consumed over the entire lifetimes of all Bikini Island residents. The typical maximum value of annual effective doses incurred under the IA/rehabilitation scenario was estimated to be $0.41 \mathrm{mSv}$; the estimated 30-, 50-, and 70-y integral doses are $0.98 \mathrm{cSv}, 1.4 \mathrm{cSv}$, and $1.6 \mathrm{cSv}$ respectively (Table 1). The average maximum annual effective dose for this IUA/rehabilitation scenario is estimated to be $1.2 \mathrm{mSv}$, and the 30-, 50-, and 70-y integral doses were estimated to be $3.1 \mathrm{cSv}, 4.3 \mathrm{cSv}$, and $5.1 \mathrm{cSv}$, respectively. Field observations indicate that the IUA scenario is unlikely to pertain to any extended period of time in the event of Bikini resettlement, and thus this scenario may be considered highly conservative (Robison et al., 1995). 
Table 1. The 30-, 50- and 70-y integral effective dose for Bikini Island residents for the soil removal/K treatment option when imported foods are available and when only local foods are consumed. $a$

\begin{tabular}{|c|c|c|c|c|c|c|c|}
\hline \multirow[b]{2}{*}{ Dietary model } & \multicolumn{7}{|c|}{ Integral effective dose, $\mathrm{CSv}$} \\
\hline & $\longrightarrow$ & IA & IUA & IA & IUA & IA & IUA \\
\hline \multicolumn{2}{|c|}{ Exposure duration $\longrightarrow$} & $30 y$ & $30 \mathrm{y}$ & $50 \mathrm{y}$ & $50 \mathrm{v}$ & $70 \mathrm{y}$ & $70 \mathrm{y}$ \\
\hline External & & 0.36 & $0.36^{\mathrm{a}}$ & 0.49 & 0.49 & 0.57 & 0.57 \\
\hline \multirow[t]{2}{*}{ Internal, } & \multicolumn{7}{|c|}{ by: } \\
\hline & \multicolumn{7}{|c|}{ Ingestion } \\
\hline $137 \mathrm{Cs}$ & & 0.53 & 2.1 & 0.72 & 2.8 & 0.85 & 3.3 \\
\hline $90 \mathrm{Sr}$ & & 0.084 & 0.59 & 0.12 & 0.86 & 0.15 & 1.0 \\
\hline $239+240 \mathrm{Pu}$ & & 0.0011 & 0.0098 & 0.0028 & 0.024 & 0.0051 & 0.044 \\
\hline \multirow[t]{2}{*}{$241 \mathrm{Am}$} & & 0.0011 & 0.0055 & 0.0026 & 0.013 & 0.0045 & 0.023 \\
\hline & \multicolumn{7}{|c|}{ Inhalation } \\
\hline $239+240 \mathrm{Pu}$ & & 0.0051 & 0.0051 & 0.013 & 0.013 & 0.023 & 0.023 \\
\hline 241Am & & 0.0038 & 0.0038 & 0.0090 & 0.0090 & 0.016 & 0.016 \\
\hline Totala & & 0.98 & 3.1 & 1.4 & 4.3 & 1.6 & 5.1 \\
\hline
\end{tabular}

a IA = model diet assuming that "imported foods are available"; IUA = model diet assuming availability of "local foods only", i.e., that "imported foods are unavailable". Adapted from Robison et al. (1995), which details corresponding assumptions made concerning dosimetric models and residential exposure scenarios.

b All values rounded to two significant digits.

For both diet models, the rehabilitation scenario assumed for the present analysis is predicted to result in an approximate 10-fold reduction in dose to potential Bikini resettlers, under the following assumptions (see Robison et al., 1995). Pre-treatment of the entire agricultural areas of Bikini Island with a highpotassium fertilizer is assumed to reduce ${ }^{137} \mathrm{Cs}$ activities in all terrestrial foods to $5 \%$ of their untreated values. Treatment is assumed to affect ingested ${ }^{137} \mathrm{Cs}$ in pork to the extent that pigs eat treatment-affected vegetation and treated vs. untreated soil. Food intakes for penned pigs are assumed to be $90 \%$ vegetation and $10 \%$ village-area soil, while those for unpenned pigs are assumed to be $90 \%$ vegetation and $10 \%$ soil from areas outside the village, where pork from penned and unpenned pigs are each assumed to comprise $50 \%$ of total pork consumed. Chicken is assumed to correspond to the scenario assumed for unpenned pigs. Coconut crabs are assumed to be taken from the southern islands of Bikini Atoll where they are plentiful (Bikini Island itself has no coconut crabs). 
Estimated dose is typically a function of distributed quantities reflecting either uncertainty (lack of knowledge concerning "the true" value of a variate) or interindividual variability (or simply "variability", referring to heterogeneity in true variate values pertaining to different people at risk). Consequently, predicted dose typically reflects both uncertainty and interindividual variability. A detailed analysis of uncertainty and variability is presented here for estimates of fallout-related radiation doses to potential Bikini Island residents. The analysis assumes that resettlement will occur in 1999, following rehabilitation measures consisting of (1) removing the top $40 \mathrm{~cm}$ of soil in the housing and village area and (2) treating the rest of the island with potassium fertilizer, as described above. Corresponding maximum 1-y and 70-y doses to hypothetical Bikini resettlers are recalculated, as described below, using approximations and Monte-Carlo procedures allowing characterization of joint uncertainty and variability (JUV) in estimated dose as a function of distributed input variates involved.

\section{Methods Used to Estimate Uncertainty and Interindividual Variability in Bikini Doses and Corresponding Population Risk}

The dose estimates listed in Table 1 were calculated using arithmetic mean values for each of the parameters in the dose models, such as body weight, residence time of radionuclides in the body, radionuclide concentrations in food and soil, dietary intake (in $\mathrm{g} \mathrm{d}^{-1}$ ), and fractional deposition of radionuclides in body compartments. Probability distributions for some of these parameters-including body weights for Marshallese females and males, corresponding dietary intakes, $\mathrm{Pu}$ and $\mathrm{Am}$ concentrations in soil, and $137 \mathrm{Cs}$ concentrations in drinking-coconut meat and fluid-are shown in figures appearing in previous reports (Robison et al., 1988, 1994a-b). Most of these data are lognormally distributed.

Estimated dose is a function of distributed quantities reflecting either uncertainty (i.e., lack of knowledge concerning "the true" value) or interindividual variability (which hereafter will be referred to simply as "variability," i.e., heterogeneity in values pertaining to different people), or both. To characterize joint uncertainty and variability (JUV) in estimated dose, it is necessary to distinguish these attributes systematically as each or both may pertain to each input variate, and then to use appropriate JUV-analytic methods (Bogen and Spear, 1987; Nazaroff et al., 1987; IAEA, 1989; Bogen, 1990,1995; NRC, 1994). These methods were used to recalculate dose to potential Bikini residents as a function of several distributed input variates. 
Uncertainty and variability were characterized for predicted total integrated doses arising from: (i) external gamma-ray exposure, (ii) $241 \mathrm{Am}$ and $239+240 \mathrm{Pu}$ inhalation and ingestion, (iii) $90 \mathrm{Sr}$ ingestion, and (iv) $137 \mathrm{Cs}$ ingestion (i.e., all the sources listed in Table 1). Expected values of the relatively minor source-specific doses (i-iii) were all calculated using the same ICRP models (Leggett, 1986; ICRP, 1988, 1990, 1991) employed by Robison et al. (1995) to calculate adult 1-y, 30-y, 50-y and 70-y doses from these sources, except for one modification accounting for greater absorption of ingested $90 \mathrm{Sr}$ in children (discussed below). To facilitate JUV analysis of total integral dose, the dominant source of potential radiological exposure on Bikini, $137 \mathrm{Cs}$ ingestion (see Table 1), was treated somewhat differently. Specifically, the onecompartment ICRP (1990) model for ingested $137 \mathrm{Cs}$ was replaced by the following structurally equivalent model:

$$
\begin{array}{ll}
q_{i j}\left(t_{i}\right)=F B R_{i j} \exp \left(-\lambda t_{i}\right) & \text { at any timet } i_{i} 0 \leq t_{i} \leq t, \\
q_{i j}(u)=-(\beta K+\lambda) q_{i}(u) & \text { for any time } u, t_{i} \leq u \leq t, \\
q_{i j}(u)=B F R_{i j} \exp \left(-\lambda t_{i}\right) \exp [-(\beta K+\lambda) u] & \text { for any time } u, t_{i} \leq u \leq t,
\end{array}
$$

in which: $q_{i j}(u)$ is the activity, in $\mathrm{Bq} \mathrm{kg}{ }^{-1}$ body weight, of ${ }^{137} \mathrm{Cs}$ in the whole body at any time $u$ following ingestion of an activity $R_{i j}$ (in Bq kg-1 body weight) of $137 \mathrm{Cs}$ contained in a food item of type $j$ at time $t_{i}, B$ represents a dietary-dose-model bias (i.e., a dose-estimation uncertainty factor) associated with $R_{i j}$, prime (") denotes differentiation with respect to time, $\lambda$ is the radiological decay rate of $137 \mathrm{Cs}$, $K=\operatorname{Ln}(2) H^{-1}$ is the biological loss rate of $137 \mathrm{Cs}$ from the dominant "slow" metabolic compartment of a reference adult (see ICRP, 1990), $F$ is the fraction of ingested dose entering this slow metabolic compartment, and $\beta$ is a factor representing uncertainty associated with $H$. Henceforth, angle brackets $(\langle\rangle)$ are used to denote mathematical expectation only with respect to uncertainty, and an overbar is used to denote expectation only with respect to interindividual variability (see Bogen, 1995).

Daily intakes $R_{i j}$ in $\mathrm{Bq} \mathrm{kg}{ }^{-1} \mathrm{~d}^{-1}$ of $137 \mathrm{Cs}$, as well as corresponding intakes of $90 \mathrm{Sr}$, in local food items of type $j$ were assumed to be obtained from independent random samples of such items collected $n_{j}$ days per year from among the possible selections of the type available on Bikini. The corresponding cumulative dose $D(t)$ from all exposure sources was estimated as:

$$
D(t)=D_{\mathrm{x}}(t)+D_{\mathrm{AmPu}}(t)+D_{\mathrm{Sr}}(t)+\int_{0}^{t} \sum_{j} \sum_{i=1}^{n_{j}} \frac{365}{n_{j}} c q_{i j}(u) \mathrm{d} u
$$


where $c$ is a unit-conversion constant, $D_{\mathbf{x}}(t)$ is the external-gamma dose modeled as interindividually variable (and not uncertain), $D_{\mathrm{AmPu}}(t)$ is the unmodified ICRPmodel estimate of total $\mathrm{Am}+\mathrm{Pu}$ inhalation+ingestion dose (which was modeled as neither uncertain nor variable, in view of its relatively minor role-see Table 1), and $D_{\mathrm{Sr}}(t)$ is the dose due to $90 \mathrm{Sr}$ ingestion (modeled as both uncertain and interindividually variable, similar to the approach taken for $137 \mathrm{Cs}-$ see Appendix). Eq. (4) was evaluated using a combination of analytic and Monte-Carlo methods detailed in the Appendix.

\section{Dose-model parameter distributions}

Using the angle-bracket and overbar notation discussed above, specific assumptions regarding distributions for each variable and/or uncertain parameter appearing or implied in Eq. (4) are discussed individually below. These assumptions are summarized in Table 2.

\section{External gamma dose}

Variability in $D_{\mathbf{x}}(t)$ was modeled using data and assumptions stated in Robison et al. (1995) (in Table 1 and the Dose Methodology section of that reference) concerning average times spent in the house, house surroundings, village area, island interior and beach/lagoon areas, and corresponding mean exposure rates. With these assumptions, it was further assumed that the daily time spent in the island interior varies triangularly over the range of 1 to $5 \mathrm{~h}$ about its assumed population average value of $3 \mathrm{~h}$. Thus, it is assumed that $D_{x}(t)=X_{\gamma} \overline{D_{x}(t)}$, where $X_{\gamma}$ is an activity-patterndependent exposure-variability factor that is triangularly distributed over the range $1 \pm(19 / 30)$.

\section{Metabolic factors for ${ }^{137} \mathrm{Cs}$}

Variability in the fraction, $F$, of ingested $137 \mathrm{Cs}$ input to the dominant biological compartment was assumed to be uniformly distributed between an uncertain lower bound ranging between 0.71 and 0.89 , and an upper bound of 1 . Thus, uncertainty in $\bar{F}$ was assumed to be uniformly distributed within $\pm 5 \%$ of an assumed expected value of 0.9 , and variability of $\langle F\rangle$ was assumed to be uniformly distributed between 0.8 and 1 . These assumptions approximately characterize the empirical data on the value of $F$ obtained for 17 individuals reported by Schwartz and Dunning (1982). 
Table 2. Parameters used in analysis of uncertainty and variability in estimated dose to hypothetical Bikini residents.

\begin{tabular}{|c|c|c|c|c|}
\hline Parameters $a$ & Symbol & $\begin{array}{c}\text { Variate } \\
\text { type }\end{array}$ & $\begin{array}{c}\text { Value or } \\
\text { distribution modelc }\end{array}$ & Unit \\
\hline Effective unit-conversion factor & $\bar{c}$ & $\mathrm{C}$ & $2.419 \times 10^{-4}$ & $\mathrm{CSv} \mathrm{kg} \mathrm{Bq}^{-1} \mathrm{y}^{-1}$ \\
\hline Radiological decay rate of $137 \mathrm{Cs}$ & $\lambda$ & C & 0.0230 & $y^{-1}$ \\
\hline External gamma expos. variability factor & $x_{\gamma}$ & $\mathrm{V}$ & $\operatorname{Tri}(11 / 30,1,49 / 30)$ & unitless \\
\hline Fraction input to slow compartment for ${ }^{137} \mathrm{Cs}$ & $F$ & UV & $\mathrm{U}(2 \bar{F}-1,1)$ & unitless \\
\hline Variability expectation of $F$ & $\bar{F}$ & $\mathrm{U}$ & $\mathrm{U}(0.855,0.945)$ & unitless \\
\hline Biological half-life of slow compartment & $H$ & $\mathrm{~V}$ & $\operatorname{LN}\left(\bar{H}-\left(h^{2} / 2\right), h\right)$ & y \\
\hline $\begin{array}{l}\text { Population-average value of } H \\
\text { Uncertainty associated with } H\end{array}$ & $\begin{array}{l}\bar{H} \\
\beta\end{array}$ & $\begin{array}{l}\mathrm{C} \\
\mathrm{U}\end{array}$ & $\begin{array}{l}110 / 365 \\
U(0.9,1.107)\end{array}$ & $\underset{\text { unitless }}{\mathrm{y}}$ \\
\hline SD of $\operatorname{Ln}(H)$-variability & $h$ & C & 0.275 & unitless \\
\hline Annual dietary intake of $137 \mathrm{Cs}$ & $R$ & UV & $\operatorname{LN}\left(\bar{R}-\left(r^{2} / 2\right), r\right)$ & $\mathrm{Bq} \mathrm{kg}{ }^{-1} \mathrm{y}^{-1}$ \\
\hline Population-average value of $R$ & $\bar{R}$ & $\mathrm{U}$ & $\mathrm{N}\left(\overline{\langle R\rangle}, \overline{\langle R\rangle} g_{R}\right)$ & $B q k^{-1} y^{-1}$ \\
\hline Expected 1999 values of $\vec{R} / 365 \mathrm{~d}$ & $\overline{\langle R\rangle} / 365 \mathrm{~d}$ & $\mathrm{C}$ & $50.1 / 70$ (IA diet), $196.7 / 70$ (IUA diet) & $\mathrm{Bq} \mathrm{kg}^{-1} \mathrm{y}^{-1}$ \\
\hline $\mathrm{SD}$ of $\operatorname{Ln}(R)$ variability & $r$ & C & 0.8217 & unitless \\
\hline $\mathrm{CV}$ of $\langle R\rangle$ variability & $g_{R}$ & C & 0.9821 & unitless \\
\hline$C V$ in $R$ due to annual diet sample uncertainty & $\gamma_{R}$ & C & 0.039 & unitless \\
\hline Cumulative dose due to ${ }^{90} \mathrm{Sr}$ ingestion by time $t$ & $D_{\mathrm{Sr}}(t)$ & UV & (see text) & $\mathrm{cSv}$ \\
\hline Factor for variability in adult ${ }^{90} \mathrm{Sr} \mathrm{GI}$ absorption & n $G$ & $\mathrm{~V}$ & $\mathrm{U}(0.50,1.5)$ & unitless \\
\hline Uncertainty (model bias) associated with $R$ & $B$ & $U$ & LN(-0.04309, 0.2936) & unitless \\
\hline Uncertainty risk per unit dose & $z$ & $\mathrm{U}$ & LN $(-7.131,0.5064)$ & $\mathrm{CSv}^{-1}$ \\
\hline
\end{tabular}

a IA = imports available, IUA = imports unavailable, $\mathrm{SD}=$ standard deviation, $\mathrm{CV}=\mathrm{SD} /$ mean.

$b \quad \mathrm{C}=$ constant, $\mathrm{U}=$ uncertainty, $\mathrm{V}=$ interindividually variable (i.e., heterogeneous), $\mathrm{UV}=$ both uncertain and heterogeneous.

c $\mathrm{U}(a, b)=$ uniformly distributed between $a$ and $b, \mathrm{LN}(a, b)=$ lognormally distributed with a geometric mean of $\exp (a)$ and a geometric $\mathrm{SD}\left(\mathrm{SD}_{\mathrm{g}}\right)$ of $\exp (b), \mathrm{N}(a, b)=$ normally distributed with mean $a$ and $\mathrm{SD} b, \operatorname{Tr}(a, b, c)=$ triangularly distributed with bounds $a$ and $c$ and mode $b$. 
Interindividual variability in the biological half-time, $H$, of the dominant slow compartment was modeled as lognormally distributed based on the data pertaining to 23 Marshallese males indicating a median of $115 \mathrm{~d}$ and $\mathrm{SD}_{\mathrm{g}}=1.23$, as shown in Figure 4 of Robison et al. (1995). For the present analysis, however, it was assumed that $\bar{H}=110 \mathrm{~d}$ and that $\mathrm{SD}_{\mathrm{g}}=1.32$ for $H$, based, respectively, on the ICRP (1979) reference mean value (used earlier) and on data reviewed by Schwartz and Dunning (1982) indicating slightly greater variability associated with the parameter among 53 individuals from whom measurements were available. A geometric mean (GM) value of $H(105.9 \mathrm{~d})$ consistent with the values selected for $\bar{H}$ and $\mathrm{SD}_{\mathrm{g}}$ was obtained using the method of moments. Uncertainty pertaining to $H$ was represented by the independent factor $\beta$ assumed to be uniformly distributed (between 0.9 and 1.107), such that the true value of $H$ pertaining to any specific individual was taken to lie within $10 \%$ of the expected value for that individual.

\section{Metabolic factors for ${ }^{90} \mathrm{Sr}$}

In contrast to the situation for potential Bikini Island resettlers, for whom ingested $90 \mathrm{Sr}$ would a relatively negligible source of radiation exposure (Robison et al., 1994a), $90 \mathrm{Sr}$ is likely to constitute a nonnegligible fraction of total dose for potential Bikini resettlers, albeit a relatively small one compared to that due to $137 \mathrm{Cs}$ (Robison et al., 1995). The ICRP (1990) biokinetic model for 90Sr (with six compartments) is much more complex than the one-compartment model used for ${ }^{137 C s,}$ which was adapted above to facilitate stochastic analysis. Data are available from which models of uncertainty and interindividual variability in $90 \mathrm{Sr}$ uptake and distribution and consequent dosimetry could be constructed (e.g., Rivera, 1967; Bennett, 1973,1977,1978; Papworth and Vennet, 1973,1984; Klusek, 1979; Leggett et al., 1982; Christy, 1984,1987a-b). However, for the present analysis, in view of the fact that $90 \mathrm{Sr}$ would play a relatively minor role for potential Bikini resettlers vis-a-vis ${ }^{137} \mathrm{Cs}$, a variability factor, $G$, was only applied explicitly to the fraction $F_{\mathrm{Sr}}(t)$ of $90 \mathrm{Sr}$ absorbed gastrointestinally at time $t$. A uniform distribution between 0.5 and 1.5 for $G$ (applied multiplicatively to $F_{\mathrm{Sr}}(t)$ ) was assumed, based on the range discussed in ICRP (1990) concerning the value 0.30 recommended as the expected value for this fraction pertaining to $D_{\mathrm{Sr}}(t)$ for adults. Due to physiological and dietary factors, $F_{\mathrm{Sr}}(t)$ absorbed gastrointestinally in infants is substantially higher, and in later childhood somewhat higher, than that it is in adults. For the present analysis, age-specific estimates for $F_{\mathrm{Sr}}(t)$ provided in ICRP (1990; Table 3-1, p. 26) were interpolated to 
derive a deterministic weighting function $W(t)$ equal to the time-weighted average of the ratio $F_{\mathrm{Sr}}(u) / 0.30$ for $0 \leq u \leq t$ (Figure 1). To obtain $D_{\mathrm{Sr}}(t)$ for any age range, $W(t)$ was multiplied by adult dose, $D_{\text {Sra }}(t)$, obtained using the ICRP (1990) adults-only model for ${ }^{90} \mathrm{Sr}$ employed by Robison et al., (1995). Additional metabolic uncertainty and variability in $D_{\mathrm{Sr}}(t)$ was assumed to be proportional to and (as a conservative assumption) completely correlated with that associated with dietary ${ }^{137} \mathrm{Cs}$ intake (see Appendix). All maximum 1-yr effective doses were calculated (conservatively) assuming that the resettling cohort arrives at age 0 (and thus incurs a maximal $90 \mathrm{Sr}$ dose).

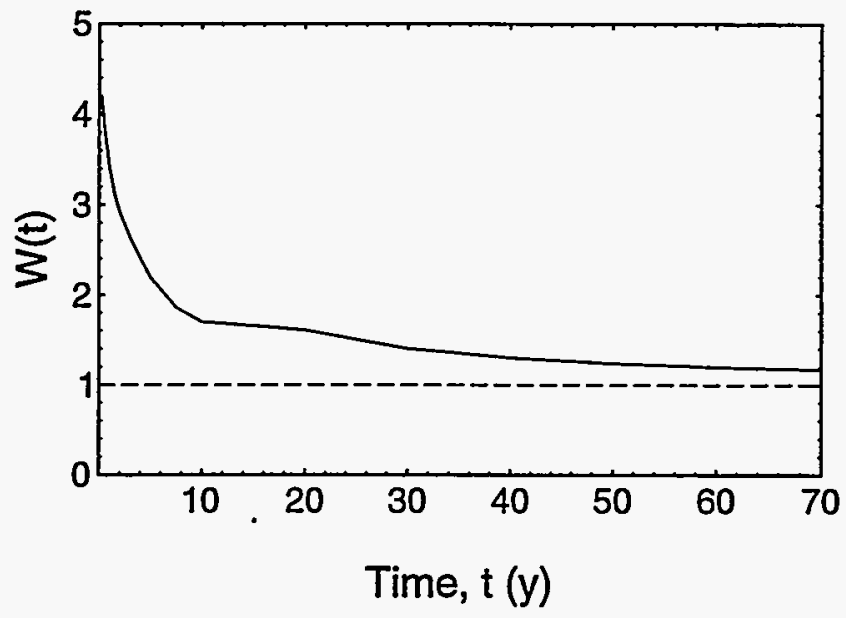

Figure 1. A weighting function $W(t)$ representing the time-weighted average of the ratio of the fraction of ingested $90 \mathrm{Sr}$ absorbed at age $t$ to its estimated adult value (0.30), based on age-specific uptake estimates presented in ICRP (1990). An adult dose obtained using the ICRP (1990) $90 \mathrm{Sr}$ adults-only model is multiplied by $W(t)$ to obtain integrated dose up to time $t$ starting with exposure at birth.

\section{Dietary intake of ${ }^{137 C s}$ and ${ }^{90} \mathrm{Sr}$}

The population-average value of expected annual intake, $\overline{\langle R\rangle}$, of total $137 \mathrm{Cs}$ activity in the LLNL model diet for hypothetical Bikini residents as of 1999 (assuming imports are available) was taken to be $365 \times 0.716 \mathrm{~Bq} \mathrm{~kg}^{-1} \mathrm{y}^{-1}$ for a reference adult, based on the analysis of food consumption survey data for 34 adult Ujelang females discussed in Robison et al. (1994a). Interindividual variability in corresponding expected daily intakes, $\left\langle R_{i j}\right\rangle$ was modeled using the empirical distribution of average daily uptakes in $\mathrm{Bq} \mathrm{kg}^{-1}$ calculated from the food-survey data for these same 34 adult Ujelang females, which was multiplicatively scaled to have expected daily population average values equal to $100 \%$ of the total mean daily $137 \mathrm{Cs}$ 
intakes corresponding to each of the two dietary scenarios considered. For potential Bikini resettlers, these expected values of food-specific $137 \mathrm{Cs}$ activities and intakes are summarized in Table 3 for the 11 major local-food items likely to be consumed. The scaled empirical distribution of $137 \mathrm{Cs}$ intake does not significantly differ from a lognormal distribution with a geometric standard deviation $\left(\mathrm{SD}_{\mathrm{g}}\right)$ of 0.8217 (Figure 2); p $>0.15$ using Stephen's modified Kolmolgorov-Smirnov, Cramer-vonMises, or Watson tests (Stephens, 1970; Pearson and Hartley, 1972). We used this lognormal distribution as the basis of our model of variability in $\langle R\rangle=365\left\langle R_{i j}\right\rangle$ for the hypothetical Bikini resettlement population. By the method of moments (Aitchison and Brown, 1957), this distribution has a corresponding coefficient of variation (CV) (i.e., standard deviation (SD) divided by expected value) with respect to modeled variability equal to $g_{R}=0.9821$.

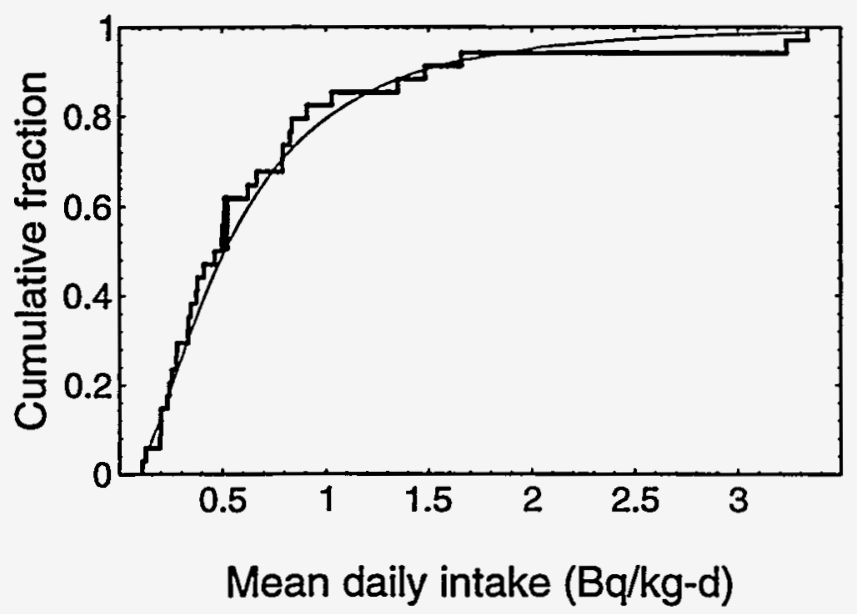

Figure 2. Sample distribution of interindividual variability in daily intake of $137 \mathrm{Cs}$ per unit body weight based on survey data for 34 adult Ujelang females (bold), shown here fit to a lognormal distribution (light) with $\mathrm{SD}_{\mathrm{g}}=2.274$ and a mean value scaled to equal $0.7157 \mathrm{~Bq} \mathrm{~kg}^{-1} \mathrm{~d}^{-1}$, the expected value for 1999 Bikini resettlers assuming imported foods are available. The Ujelang survey data are discussed further in Robison et al. (1994a). 
Table 3. Diet Model-Bikini Island for adults for ${ }^{137} \mathrm{Cs}$ Ingestion. $a, b$

\begin{tabular}{|c|c|c|c|c|c|c|c|c|c|c|}
\hline \multirow[b]{3}{*}{ Local foods } & \multirow{3}{*}{$\begin{array}{c}\text { Intake: } \\
\text { Local Foods } \\
\text { Only } \\
\left(\mathrm{g} \mathrm{d}^{-1}\right) \\
\mathrm{L}\end{array}$} & \multirow{3}{*}{$\begin{array}{c}\text { Intake: } \\
\text { Local + } \\
\text { Imported } \\
\left(\mathrm{g} \mathrm{d}^{-1}\right) \\
\text { I }\end{array}$} & \multirow{2}{*}{\multicolumn{2}{|c|}{${ }^{137}$ Cs Activity }} & \multicolumn{6}{|c|}{${ }^{137} \mathrm{Cs}$ Intake } \\
\hline & & & & & \multicolumn{3}{|c|}{ Local Only } & \multicolumn{3}{|c|}{ Imports Available } \\
\hline & & & $\begin{array}{c}\text { Mean } \\
\left(\mathrm{Bq} \mathrm{g}^{-1}\right) \\
\mathrm{C}\end{array}$ & $\begin{array}{c}\text { SD/Mean } \\
\gamma_{C}\end{array}$ & $\begin{array}{c}\text { Mean } \\
\left(\mathrm{Bq} \mathrm{d}^{-1}\right) \\
A=\mathrm{LC}\end{array}$ & $\begin{array}{c}\text { Var. } \\
\left(\mathrm{Bq} \mathrm{d}^{-1}\right)^{2} \\
\sigma^{2}\end{array}$ & $\begin{array}{c}\text { SDMean } \\
\gamma\end{array}$ & $\begin{array}{c}\text { Mean } \\
\left(\text { Bq d }^{-1}\right) \\
B=I C\end{array}$ & $\begin{array}{c}\text { Var. } \\
\left(\mathrm{Bq} \mathrm{d}^{-1}\right)^{2} \\
\sigma^{2}\end{array}$ & SD/Mean \\
\hline \multicolumn{11}{|l|}{ Coconut } \\
\hline Milk $^{d}$ & 122 & 51.9 & 0.268 & 0.644 & 32.6 & 442 & & 13.9 & 80.2 & \\
\hline Meat & 181 & 31.7 & 0.147 & 0.739 & 26.6 & 386 & & 4.66 & 11.9 & \\
\hline Copra & 71.4 & 12.2 & 0.268 & 0.644 & 19.1 & 152 & & 3.27 & 4.43 & \\
\hline Juice & 334 & 99.1 & 0.0577 & 0.777 & 19.3 & 224 & & 5.72 & 19.7 & \\
\hline Totalc & 708 & & 0.138 & & 97.6 & & 0.355 & & & \\
\hline Totale & & 195 & 0.141 & & & & & 27.6 & & 0.391 \\
\hline \multicolumn{11}{|l|}{ Pork } \\
\hline Heart & 0.620 & 0.310 & 0.980 & 1.10 & 0.608 & 0.447 & & 0.304 & 0.112 & \\
\hline Muscle & 13.9 & 5.67 & 1.57 & 0.635 & 21.9 & 193 & & 8.90 & 32.0 & \\
\hline Liver & 6.70 & 2.60 & 0.812 & 0.912 & 5.44 & 24.6 & & 2.11 & 3.71 & \\
\hline Totalc & 21.24 & & 1.31 & & 27.9 & & 0.529 & & & \\
\hline Totalc & & 8.58 & 1.32 & & & & & 11.3 & & 0.528 \\
\hline \multicolumn{11}{|l|}{ Chicken } \\
\hline Muscle & 31.2 & 8.36 & 0.0213 & $0.635^{\mathrm{e}}$ & 0.665 & 0.178 & & 0.178 & 0.0128 & \\
\hline Liver & 17.7 & 4.50 & $0.0213^{f}$ & $0.912 \mathrm{~g}$ & 0.377 & 0.118 & & 0.0959 & 0.00764 & \\
\hline Gizzard & 3.32 & 1.66 & $0.0213^{f}$ & $0.912^{g}$ & 0.0707 & 0.00416 & & 0.0354 & 0.00104 & \\
\hline Totalc & 52.2 & & 0.0213 & & 1.11 & & 0.493 & & & \\
\hline Totalc & & 14.52 & 0.0213 & & & & & 0.309 & & 0.474 \\
\hline Breadfruit & 186 & 27.2 & 0.0190 & 0.584 & 3.54 & 4.27 & 0.584 & 0.517 & 0.0911 & 0.584 \\
\hline Pandanus & 65.0 & 9.16 & 0.194 & 0.848 & 12.6 & 114 & 0.848 & 1.78 & 2.27 & 0.848 \\
\hline Sprouting Coconut ${ }^{d}$ & 122 & 7.79 & 0.268 & 0.644 & 32.8 & 446 & 0.644 & 2.09 & 1.81 & 0.644 \\
\hline Papaya & 27.0 & 6.59 & 0.110 & 1.34 & 2.97 & 15.8 & 1.34 & 0.725 & 0.944 & 1.34 \\
\hline Arrowroot & 94.8 & 3.93 & 0.0543 & 0.413 & 5.15 & 4.52 & 0.413 & 0.213 & 0.00777 & 0.413 \\
\hline Pumpkin & 5.44 & 1.24 & 0.0587 & 1.18 & 0.319 & 0.142 & 1.18 & 0.0728 & 0.00738 & 1.18 \\
\hline
\end{tabular}


Table 3. Diet Model-Bikini Island for adults for ${ }^{137} \mathrm{Cs}$ Ingestion. $\mathrm{a}, \mathrm{b}$

\begin{tabular}{|c|c|c|c|c|c|c|c|c|c|c|}
\hline \multirow[b]{3}{*}{ Local foods } & \multirow{3}{*}{$\begin{array}{c}\text { Intake: } \\
\text { Local Foods } \\
\text { Only } \\
\left(\mathrm{g} \mathrm{d}^{-1}\right) \\
\mathrm{L}\end{array}$} & \multirow{3}{*}{$\begin{array}{c}\text { Intake: } \\
\text { Local + } \\
\text { Imported } \\
\left(\mathrm{g} \mathrm{d}^{-1}\right) \\
\mathrm{I}\end{array}$} & \multirow{2}{*}{\multicolumn{2}{|c|}{${ }^{137}$ Cs Activity }} & \multicolumn{6}{|c|}{${ }^{137} \mathrm{Cs}$ Intake } \\
\hline & & & & & \multicolumn{3}{|c|}{ Local Only } & \multicolumn{3}{|c|}{ Imports Available } \\
\hline & & & $\begin{array}{c}\text { Mean } \\
\left(\mathrm{Bq} \mathrm{g}^{-1}\right) \\
\mathrm{C}\end{array}$ & $\begin{array}{c}\text { SD/Mean } \\
\gamma_{C}\end{array}$ & $\begin{array}{c}\text { Mean } \\
\left(\mathrm{Bq} \mathrm{d}^{-1}\right) \\
A=\mathrm{LC}\end{array}$ & $\begin{array}{c}\text { Var. } \\
\left(\mathrm{Bq} \mathrm{d}^{-1}\right)^{2} \\
\sigma^{2}\end{array}$ & $\begin{array}{c}\text { SDMean } \\
\gamma\end{array}$ & $\begin{array}{c}\text { Mean } \\
\left(\mathrm{Bq} \mathrm{d}^{-1}\right) \\
B=\mathrm{IC}\end{array}$ & $\begin{array}{c}\text { Var. } \\
\left(\mathrm{Bq} \mathrm{d}^{-1}\right)^{2} \\
\sigma^{2}\end{array}$ & $\begin{array}{c}\text { SD/Mean } \\
\gamma\end{array}$ \\
\hline Marsh. Cake & 0.00 & 11.7 & 0.268 & 0.644 & 0.00 & 0.00 & 0.00 & 3.14 & 4.08 & 0.644 \\
\hline Coconut Crabs & 25.0 & 3.13 & 0.366 & 0.604 & 9.15 & 30.5 & 0.604 & 1.15 & 0.479 & 0.604 \\
\hline Subtotal & 1307 & & 0.148 & & 193 & & $0.0274^{h}$ & & & \\
\hline Subtotal & & 289 & 0.169 & & & & & 48.9 & & $0.0392^{h}$ \\
\hline$\%$ of Total & 42 & 22 & & & 98.2 & & & 97.5 & & \\
\hline
\end{tabular}

a Three significant figures are shown for the purpose of calculating corresponding mean, standard deviation (SD), variance ( $\left.\sigma^{2}\right)$ and coefficientof-variation $(\gamma)$ values.

${ }^{b}$ Local-foods-only, local+imported foods intakes and ${ }^{137} \mathrm{Cs}$ activities for specific foods decay corrected to 1999, are from Robison et. al. (1995).

c Mean and SD values for totals listed under Coconut, Pork and Chicken were calcualated using subitem-specific intake weights. For example,

$\vec{N}$ for a given food item (e.g., coconut, consisting of $\mathrm{m}=4$ constituents) with the local foods only diet, $\mathrm{A}_{i}=\mathrm{L}_{i} \mathrm{C}_{i}, \sigma_{i}=\mathrm{A}_{i} \gamma_{\mathrm{c} i}, \gamma=\left(\sum_{i=1}^{m} \sigma_{i}^{2}\right)^{1 / 2}\left(\sum_{i=1}^{m} A_{i}\right)^{-1}$.

$\mathrm{d}$ Assumed to equal copra meat.

e Assumed to equal pork muscle.

$\mathrm{f}_{\text {Assumed to equal chicken muscle. }}$

$\mathrm{g}$ Assumed to equal pork liver.

$\mathrm{h}$ The $\gamma$ value given for the subtotal of all 14 items listed, e.g., from a local-foods-diet, is the annual value caculated as $g=\left(\sum_{j=1}^{11} A_{j}\right)^{-1}\left(\sum_{j=1}^{11} A_{j}^{2} g_{j}^{2} n_{j}^{-1}\right)^{1 / 2}$ where $\mathrm{n}_{j}$ is the number of samples of food type $j$ eaten per year, assumed to be 12,52, and 182.5 for pork-related, chicken-related and other items, respectively (see Appendix). 
The distributional form and $g_{R}$ value assumed for 137Cs intake discussed above was assumed also to pertain to interindividual variability in lifetime-average daily ingestion of $90 \mathrm{Sr}$. Food-specific $90 \mathrm{Sr}$ activities and intakes for potential Bikini resettlers, under the two dietary scenarios considered, are summarized in Table 4. A comparison of Tables 3 and 4 reveals that $137 \mathrm{Cs}$ and $90 \mathrm{Sr}$ intakes for the 11 major local-food items considered are uncorrelated under both dietary scenarios $|r|<0.16$, $p \approx 1$ ). Thus, persons who might consume relatively large amounts of relatively $137 \mathrm{Cs}$-rich items would not necessarily be consuming large $90 \mathrm{Sr}$ doses relative to others. Therefore, the simplifying assumption made in the present analysis, that interindividual variabilities in lifetime average rates of $137 \mathrm{Cs}$ and $90 \mathrm{Sr}$ ingestion are completely correlated, is likely to be conservative.

Uncertainty due to random dietary sampling associated with daily $137 \mathrm{Cs}$ intake for any given individual about that individual's mean daily level was estimated under the diet-model assumptions stated above such that local foods of type $j$ are randomly and independently sampled $n_{j}$ times per year from among Bikini sources. Table 3 lists predicted amounts and measured inter-sample variability of $137 \mathrm{Cs}$ in 11 major food items local to Bikini. For this analysis, the activities associated with these 11 items were scaled to correspond to an assumption that these items comprise $100 \%$ of the local foods in either of the two dietary scenarios considered. Each corresponding $\mathrm{CV}, \gamma_{R_{i j}}=\sigma_{R_{i j}} / \overline{\left\langle R_{i j}\right\rangle}$, with respect to presumed dietary sampling error was assumed to be the measured value appearing in Table 3, and was assumed to pertain to every individual in the modeled exposed population. For this purpose, the local food items appearing in Table 3 were divided into three types (and the corresponding indicated annual sample sizes were assumed): pork-related items $\left(n_{1}\right.$ $=12)$, chicken-related items $\left(n_{2}=52\right)$, and other items $\left(n_{3}=182.5\right)$. If follows that uncertainty due to random daily dietary sampling associated with annual $137 \mathrm{Cs}$ intake is expected to be approximately normally distributed about its expected value, with an SD value inversely proportional to the square root of the total exposure time considered (see Appendix).

The Gaussian uncertainty model for random dietary sampling associated with daily ${ }^{137 C s}$ intake also pertains to ingested $90 \mathrm{Sr}$. Because the $\mathrm{CV}$ listed for

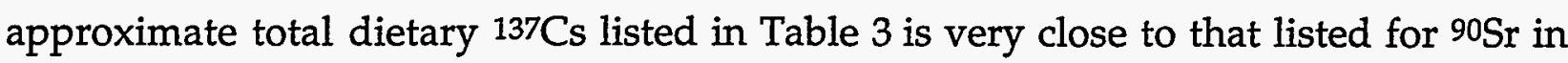
Table 4, the distribution for uncertainty in $137 \mathrm{Cs}$ intake due to dietary sampling was 
Table 4. Diet Model-Bikini Island for adults for ${ }^{90} \mathrm{Sr}$ Ingestion.. $\mathrm{a} b$

\begin{tabular}{|c|c|c|c|c|c|c|c|c|c|c|}
\hline \multirow[b]{3}{*}{ Local foods } & \multirow{3}{*}{$\begin{array}{l}\text { Intake: } \\
\text { Local Foods } \\
\text { Only } \\
\left(\mathrm{g} \mathrm{d}^{-1}\right) \\
\text { L }\end{array}$} & \multirow{3}{*}{$\begin{array}{c}\text { Intake: } \\
\text { Local + } \\
\text { Imported } \\
\left(\mathrm{g} \mathrm{d}^{-1}\right) \\
\text { I }\end{array}$} & \multirow{2}{*}{\multicolumn{2}{|c|}{ Sr-90 Activity }} & \multicolumn{6}{|c|}{${ }^{90} \mathrm{Sr}$ Intake } \\
\hline & & & & & \multicolumn{3}{|c|}{ Local Only } & \multicolumn{3}{|c|}{ Imports Available } \\
\hline & & & $\begin{array}{c}\text { Mean } \\
\left(\mathrm{Bq} \mathrm{g}^{-1}\right) \\
\mathrm{C}\end{array}$ & $\begin{array}{c}\text { SD/Mean } \\
\gamma_{C}\end{array}$ & $\begin{array}{c}\text { Mean } \\
(\text { Bq d-1) } \\
A=\mathrm{LC}\end{array}$ & $\begin{array}{c}\text { Var. } \\
\left(\mathrm{Bq} \mathrm{d}^{-1}\right)^{2} \\
\sigma^{2}\end{array}$ & $\begin{array}{c}\text { SD/Mean } \\
\gamma\end{array}$ & $\begin{array}{c}\text { Mean } \\
\left(B \mathrm{~d}^{-1}\right) \\
B=\mathrm{IC}\end{array}$ & $\begin{array}{c}\text { Var. } \\
\left(\mathrm{Bq} \mathrm{d} \mathrm{d-1}^{-1}\right)^{2} \\
\sigma^{2}\end{array}$ & SD/Mean \\
\hline \multicolumn{11}{|l|}{ Coconut } \\
\hline Milkd & 122 & 51.9 & 0.00321 & 0.915 & 0.391 & 0.128 & & 0.167 & 0.0232 & \\
\hline Meat & 181 & 31.7 & 0.00586 & 0.612 & 1.06 & 0.420 & & 0.186 & 0.0129 & \\
\hline Copra & 71.4 & 12.2 & 0.00321 & 0.915 & 0.229 & 0.0440 & & 0.0392 & 0.00128 & \\
\hline Juice & 334 & 99.1 & 0.000452 & 0.682 & 0.151 & 0.0106 & & 0.0448 & 0.000933 & \\
\hline Totalc & 708 & & 0.00259 & & 1.83 & & 0.424 & & & \\
\hline Totalc & & 195 & 0.00224 & & & & & 0.436 & & 0.449 \\
\hline \multicolumn{11}{|l|}{ Pork } \\
\hline Heart & 0.620 & 0.310 & 0.00150 & 0.512 & 0.000930 & $2.27 \times 10^{-7}$ & & 0.000465 & $5.67 \times 10^{-8}$ & \\
\hline Muscle & 13.9 & 5.67 & 0.00152 & 0.500 & 0.0212 & 0.000112 & & 0.00862 & $1.86 \times 10^{-5}$ & \\
\hline Liver & 6.70 & 2.60 & 0.00292 & 1.06 & 0.0196 & 0.000430 & & 0.00759 & $6.48 \times 10^{-5}$ & \\
\hline Totalc & 21.2 & & 0.00196 & & 0.0417 & & 0.559 & & & \\
\hline Totalc & & 8.58 & 0.00194 & & & & & 0.0167 & & 0.548 \\
\hline \multicolumn{11}{|l|}{ Chicken } \\
\hline Muscle $\mathrm{e}^{\mathrm{e}}$ & 31.2 & 8.36 & 0.00152 & 0.500 & 0.0474 & 0.000562 & & 0.0127 & $4.04 \times 10^{-5}$ & \\
\hline Liver $^{\mathrm{e}}$ & 17.7 & 4.50 & 0.00152 & 0.500 & 0.0269 & 0.000181 & & 0.00684 & $1.17 \times 10^{-5}$ & \\
\hline Gizzarde & 3.32 & 1.66 & 0.00152 & 0.500 & 0.00505 & $6.37 \times 10^{-6}$ & & 0.00252 & $1.59 \times 10^{-6}$ & \\
\hline Total $^{c}$ & 52.2 & & 0.00152 & & 0.0793 & & 0.345 & & & \\
\hline Totalc & & 14.5 & 0.00152 & & & & & 0.0221 & & 0.332 \\
\hline Breadfruit & 186 & 27.2 & 0.0690 & 0.898 & 12.8 & 133 & 0.898 & 1.88 & 2.84 & 0.898 \\
\hline Pandanus & 65.0 & 9.16 & 0.120 & 1.10 & 7.80 & 73.6 & 1.10 & 1.10 & 1.46 & 1.100 \\
\hline Sprouting Coconut ${ }^{d}$ & 122 & 7.79 & 0.00321 & 0.915 & 0.393 & 0.129 & 0.915 & 0.0250 & 0.000524 & 0.915 \\
\hline Papaya & 27.0 & 6.59 & 0.0486 & 0.580 & 1.31 & 0.579 & 0.580 & 0.320 & 0.0345 & 0.580 \\
\hline Arrowroot & 94.8 & 3.93 & 0.0676 & 0.563 & 6.41 & 13.0 & 0.563 & 0.266 & 0.0224 & 0.563 \\
\hline
\end{tabular}


Table 4. Diet Model-Bikini Island for adults for ${ }^{90} \mathrm{Sr}$ Ingestion. $\mathrm{a}, \mathrm{b}$

\begin{tabular}{|c|c|c|c|c|c|c|c|c|c|c|}
\hline \multirow[b]{3}{*}{ Local foods } & \multirow{3}{*}{$\begin{array}{c}\text { Intake: } \\
\text { Local Foods } \\
\text { Only } \\
\left(\mathrm{g} \mathrm{d}^{-1}\right) \\
\mathrm{L}\end{array}$} & \multirow{3}{*}{$\begin{array}{c}\text { Intake: } \\
\text { Local + } \\
\text { Imported } \\
\left(\mathrm{g} \mathrm{d}^{-1}\right) \\
\mathrm{I}\end{array}$} & & & \multicolumn{6}{|c|}{${ }^{90} \mathrm{Sr}$ Intake } \\
\hline & & & \multicolumn{2}{|c|}{ Sr-90 Activity } & \multicolumn{3}{|c|}{ Local Only } & \multicolumn{3}{|c|}{ Imports Available } \\
\hline & & & $\begin{array}{c}\text { Mean } \\
\left(\mathrm{Bq} \mathrm{g}^{-1}\right) \\
\mathrm{C}\end{array}$ & SD/Mean & $\begin{array}{c}\text { Mean } \\
\left(\mathrm{Bq} \mathrm{d}^{-1}\right) \\
A=\mathrm{LC}\end{array}$ & $\begin{array}{c}\text { Var. } \\
\left(\text { Bq d d }^{-1}\right)^{2} \\
\sigma^{2}\end{array}$ & SD/Mean & $\begin{array}{c}\text { Mean } \\
\left(\mathrm{Bq} \mathrm{d}^{-1}\right) \\
B=\mathrm{IC}\end{array}$ & $\begin{array}{c}\text { Var. } \\
\left(\mathrm{Bq} \mathrm{d}^{-1}\right)^{2} \\
\sigma^{2}\end{array}$ & SD/Mean \\
\hline Pumpkin & 5.44 & 1.24 & 0.0676 & 0.563 & 0.368 & 0.0429 & 0.563 & 0.0838 & 0.00223 & 0.563 \\
\hline Marsh. Cake d & 0.00 & 11.7 & 0.00321 & 0.915 & 0.00 & 0.00 & 0.00 & 0.0376 & 0.00118 & 0.915 \\
\hline Coconut Crabs & 25.0 & 3.13 & 0.0518 & 0.534 & 1.30 & 0.478 & 0.534 & 0.162 & 0.00750 & 0.534 \\
\hline Subtotal & 1307 & & 0.0248 & & 32.4 & & $0.0340^{f}$ & & & \\
\hline Subtotal & & 289 & 0.0150 & & & & & 4.35 & & $0.0358^{f}$ \\
\hline$\%$ of Total & 42 & 22 & & & 97.8 & & & 92.5 & & \\
\hline
\end{tabular}

a Three significant figures are shown for the purpose of calculating corresponding mean, standard deviation (SD), variance ( $\left.\sigma^{2}\right)$ and coefficientof-variation $(\gamma)$ values.

b Local-foods-only, local+imported foods intakes and ${ }^{90} \mathrm{Sr}$ activities for specific foods decay corrected to 1999, are from Robison et. al. (1995). $\overrightarrow{\mathrm{c}}$

${ }^{c}$ Mean and SD values for totals listed under Coconut, Pork and Chicken were calcualated using subitem-specific intake weights. For example,

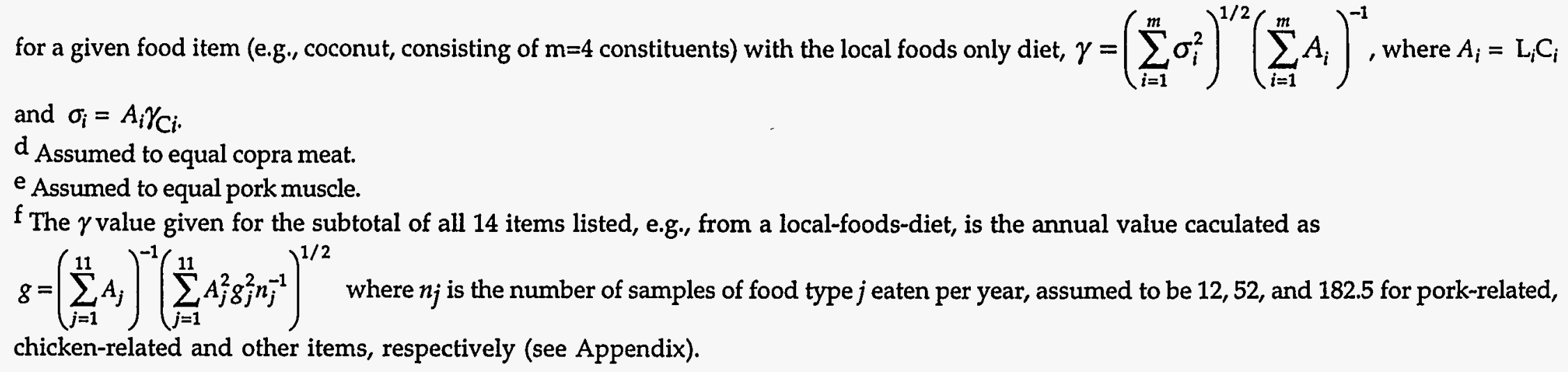


used as the corresponding distribution for $90 \mathrm{Sr}$, after scaling for the relative difference between the population-average values assumed for dietary $137 \mathrm{Cs}$ and 90Sr intakes listed in Table 1 (see Appendix). However, an analysis of measured concentrations of $137 \mathrm{Cs}$ and $90 \mathrm{Sr}$ in samples of drinking-coconut meat obtained from 70 different coconuts on Bikini Island (Figure 3) indicates that ${ }^{137 \mathrm{Cs} \text { and }}{ }^{90 \mathrm{Sr}}$ concen-

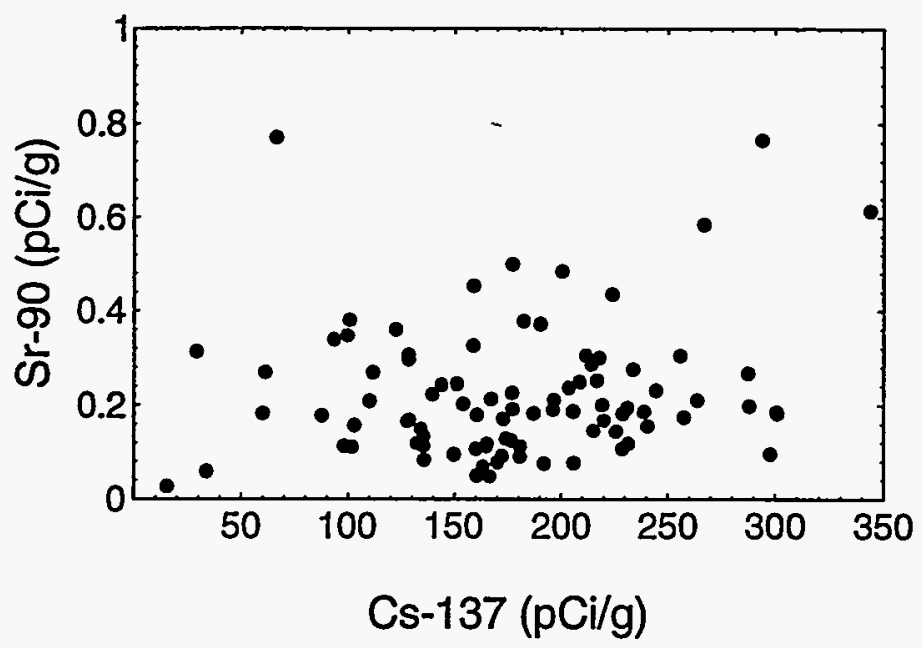

Figure 3. Scatterplot of measured concentrations of ${ }^{137} \mathrm{Cs}$ and $90 \mathrm{Sr}$ in samples of drinking-coconut meat obtained from 70 different coconuts on Bikini Island.

trations are uncorrelated in this major local-food source on Bikini $(r=0.15, \mathrm{p}=0.15)$. Thus, uncertainty in ${ }^{90} \mathrm{Sr}$ ingestion due to dietary sampling of different activities present on Bikini was assumed to be statistically independent of that pertaining to 137 Cs.

Model uncertainty (i.e., misspecification error) was estimated directly from the data shown in Figure 3 of Robison et al. (1994a) relating LLNL model-diet predictions assuming imported foods are available, and corresponding Brookhaven National Laboratory measurements of whole-body $137 \mathrm{Cs}$ dose among different samples of Marshallese people tested during the period 1977-1983. The mean of the six measured- to predicted-burden ratios shown is $1.25 \pm 0.37$ (differing insignificantly from $1, \mathrm{p}>0.16$ by T-test). Based on these data, an uncertainty-CV of $30 \%$ was assumed, and model uncertainty for the LLNL model diet assuming imported foods are available, was characterized as a corresponding lognormally distributed factor $B$ with expectation 1 and $\mathrm{SD}_{\mathrm{g}}=1.34$. This factor was assumed also to apply to estimated ${ }^{90} \mathrm{Sr}$ dose. 


\section{Population Risk}

Predicted population risk $I$ (here taken as the number of fallout-induced cancer fatalities) necessarily depends on the size, $N$, and age distribution of the population involved in any Bikini resettlement. To estimate $I$ under both dietary models considered, it was assumed that resettlement occurs in 1999 and (a) that $N=200$ or (b) that $N=2,000$ but (due to the carrying capacity of a resettled Bikini) that only 200 resettlers will be eating non-imported foods (under either dietary scenario considered). The uncertainty distribution of $I$-which, e.g., is required to calculate $\operatorname{Prob}(I=0)$, the probability of zero cases-was approximated by the method of Bogen and Spear (1987), treating $I$ as compound-Poisson-distributed with an uncertain (population-average dose) parameter here taken to be $N Z \overline{D(70)}$, where $Z$ is an uncertain "risk" factor specifying total cancer (leukemia + nonleukemia) mortality risk-per-unit dose. Based on the BEIR V (NRC, 1990) prediction of total cancer (leukemia + nonleukemia) fatalities for males and females likely to be caused by chronic low-LET radiation exposure and associated analysis of statistical and modelrelated errors, a risk factor $Z_{b}$ was taken to be approximately lognormally distributed, with expectation $0.0008 \mathrm{cSv}^{-1}$ and $\mathrm{SD}_{\mathrm{g}}=0.5064$, for a cohort resettling Bikini at birth. This expected value of $0.0008 \mathrm{cSv}^{-1}$ is the BEIR V (NRC, 1990) recommended population-weighted average value of $0.0008 \mathrm{cSv}^{-1}$ for acute low-LET radiation exposure, divided by the approximate factor of two recommended as an adjustment for estimating risk due to cumulative chronic exposure, and multiplied by a second approximate factor of two recommended as an adjustment for estimating risk associated with exposures specifically during childhood (given that a disproportionate amount of cumulative dose to Bikini resettlers would occur during the earlier years post resettlement, due to radiological decay of $137 \mathrm{Cs}$ and 90Sr). Because the latter factor of two would not apply to adults accompanying resettling infants and youth, $Z_{\mathrm{b}}$ was assumed to pertain to a fraction $f$ of the resettling population, and $Z_{b} / 2$ was assumed to pertain to $100(1-f) \%$ of the resettling population. Based on the likelihood that there would be a high proportion of infants and children among potential Bikini resettlers, the fraction $f$ was assumed to be 0.5 . Thus, the overall risk factor $Z$ was taken to be equal to $Z_{b}$ and $Z_{b} / 2$ with equal likelihood. The factor $Z$ (conservatively) does not reflect the possibility, given current fundamental radiobiological uncertainties, that the true risk due to lowlevel chronic radiation exposures, like those predicted for Bikini residents, may be zero. 


\section{Estimated Uncertainty and Interindividual Variability in Bikini Doses, \& Corresponding Estimated Population Risk}

The results of the JUV analysis of estimated dose to potential Bikini resettlers are summarized in Table 5 and Figures 4-6. Specifically, Figures $4 \mathrm{a}$ and $4 \mathrm{c}$ plot the calculated distributions for $\langle D(70)\rangle$ (characterizing interindividual variability in expected 70-y effective integral dose) and $\overline{D(70)}$ (characterizing uncertainty in population-average 70-y effective integral dose), and their corresponding MonteCarlo sampling errors, under the assumption that imported foods will be available. Figures $4 \mathrm{~b}$ and $4 \mathrm{~d}$ plot the calculated distributions for $\langle D(70)\rangle$ and $\overline{D(70)}$, and their corresponding Monte-Carlo sampling errors, under the assumption that imported foods will not be available (i.e., for a local-foods-only diet). Note that the 99.5th percentile values of $\overline{D(70)}$ listed in Table 5 represent the maximum-likelihood values of dose to the corresponding persons receiving the maximum 70-y doses among all persons exposed under the IA and IUA diet assumptions, assuming an exposed population size of 200 (NRC, 1994; Bogen, 1995).

Table 5. Summary of uncertainty and interindividual variability in estimated integral effective doses for hypothetical Bikini Island residents, assuming 1999 resettlement after soil removal/K treatment and availability and nonavailability of imported foods.

\begin{tabular}{|c|c|c|c|c|c|}
\hline \multirow[b]{2}{*}{ Dietary model $\longrightarrow$} & & \multicolumn{4}{|c|}{ Dose and exposure scenario ${ }^{a}$} \\
\hline & & IA & IUA & IA & IUA \\
\hline \multicolumn{2}{|l|}{ Exposure duration $\longrightarrow$} & $\begin{array}{c}\operatorname{Max} 1-y \\
(\mathrm{mSv})\end{array}$ & $\begin{array}{c}\operatorname{Max} 1-y \\
(\mathrm{mSv})\end{array}$ & $\begin{array}{l}70 y \\
(\mathrm{cSv})\end{array}$ & $\begin{array}{l}70 y \\
(\mathrm{cSv})\end{array}$ \\
\hline Distributed characteristic & Estimator ${ }^{b}$ & & & & \\
\hline \multirow[t]{5}{*}{ Interindividual variability } & $Q(0.025)$ & 0.17 & 0.31 & 0.65 & 1.2 \\
\hline & $Q(0.50)$ & 0.36 & 1.0 & 1.3 & 3.8 \\
\hline & EV & 0.45 & 1.4 & 1.6 & 5.2 \\
\hline & $Q(0.975)$ & 1.3 & 4.9 & 4.5 & 18 \\
\hline & $Q(0.995)$ & 2.0 & 8.2 & 7.3 & 31 \\
\hline \multirow[t]{5}{*}{ Uncertainty } & $Q(0.025)$ & - & - & 1.1 & 3.0 \\
\hline & $Q(0.50)$ & - & - & 1.6 & 5.0 \\
\hline & EV & - & - & 1.6 & 5.2 \\
\hline & $Q(0.975)$ & - & - & 2.4 & 8.7 \\
\hline & $Q(0.995)$ & - & - & 2.8 & 10. \\
\hline
\end{tabular}

a IA = model diet assuming that "imported foods are available"; IUA = model diet assuming availability of "local foods only", i.e., that "imported foods are unavailable". Values listed are rounded to two significant digits; - = not calculated.

b $\mathrm{Q}(p)=$ the $p$ th quantile or fractile $=100 p$ th percentile; EV $=$ expected value. The Monte-Carlo coefficient of variation of the mean (CVM = standard error of the mean (SEM) divided by the mean) of all listed fractile estimates is $<2 \%$, the CVM of listed $\mathrm{EV}$ values is $<0.2 \%$. 

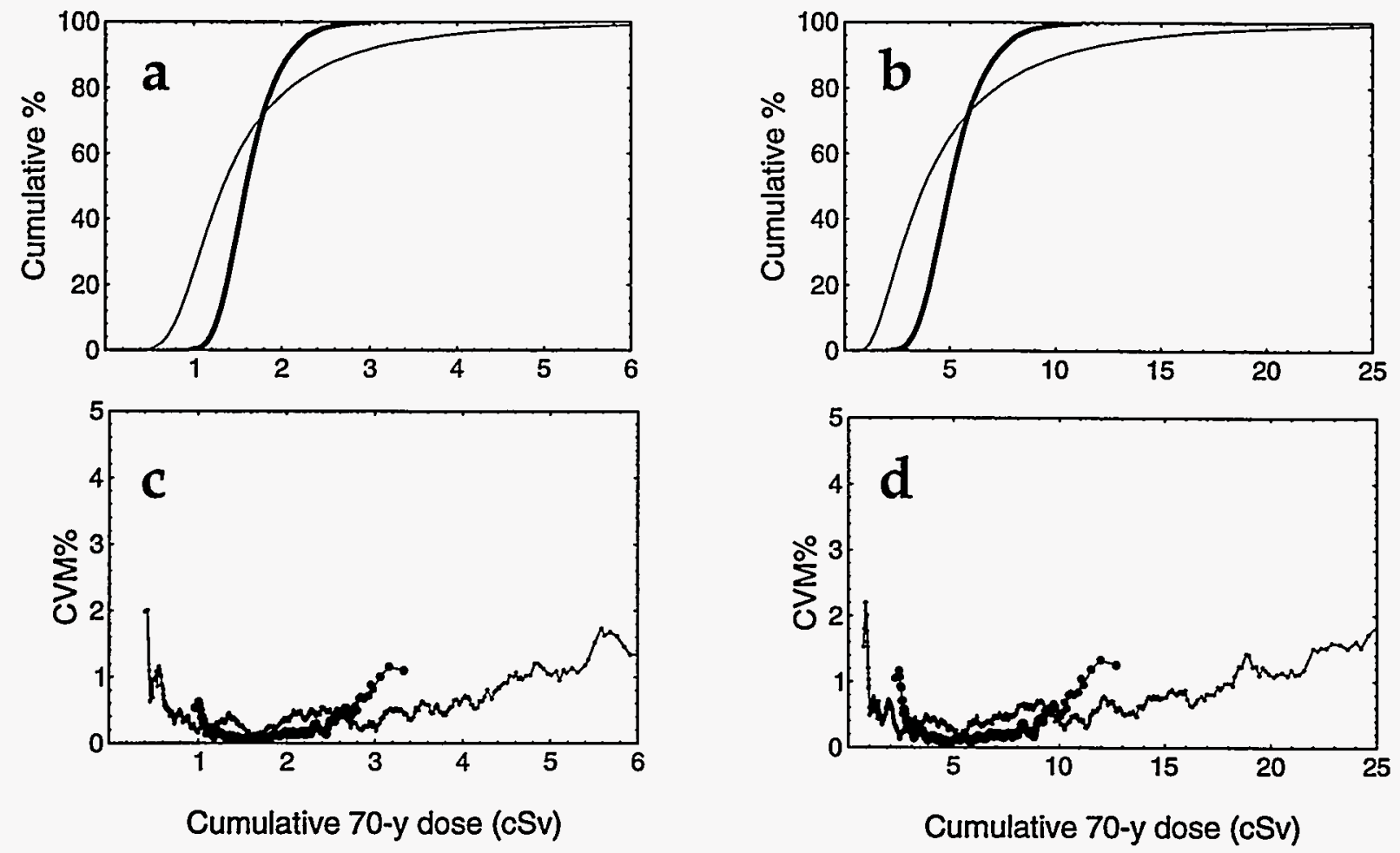

Figure 4. (a-b) Cumulative relative-frequency distributions for $\langle D(70)\rangle$ (light curves, characterizing interindividual variability in expected $70-y$ effective integral dose) and $\overline{D(70)}$ (bold curves, characterizing uncertainty in population-average $70-y$ effective integral dose). (c-d) Corresponding Monte-Carlo sampling errors, defined as the coefficient of variation of the mean ( $=$ standard error of the mean divided by the mean) of the $i$ th ordered value of 10 samples of 2000 simulated variate values, for $i$ $=1,2, \ldots, 2000$ (light and bold point sets refer to $\langle D(70)\rangle$ and $\overline{D(70)}$, respectively). Plots pairs $(a, c)$ and $(b, d)$ correspond to imports-available and local-foods-only diet assumptions, respectively.

Figures $5 \mathrm{a}$ and $5 \mathrm{c}$ plot the calculated distribution for $\operatorname{Max}(\langle D(1)\rangle)$ (characterizing interindividual variability in the maximum value of expected 1-y effective integral doses, regardless of which years each of these person-specific maxima happen to fall in), and its corresponding Monte-Carlo sampling error, under the assumption that imported foods will be available. Figures $5 \mathrm{~b}$ and $5 \mathrm{~d}$ plot the calculated distribution for $\operatorname{Max}(\langle D(1)\rangle)$ and its corresponding Monte-Carlo sampling error under the assumption that imported foods will not be available. The estimated maximum 1-yr doses are predicted to fall in years 1999, 2000, 2001, and 2002 for $~ 0.1 \%, 38.5 \%, 59.5 \%$ and $1.9 \%$ of residents if imports are assumed to be available, and for $\sim 0 \%, 4.5 \%$, $88.1 \%$ and $7.4 \%$ of residents if imports are not assumed to be available. The year of 

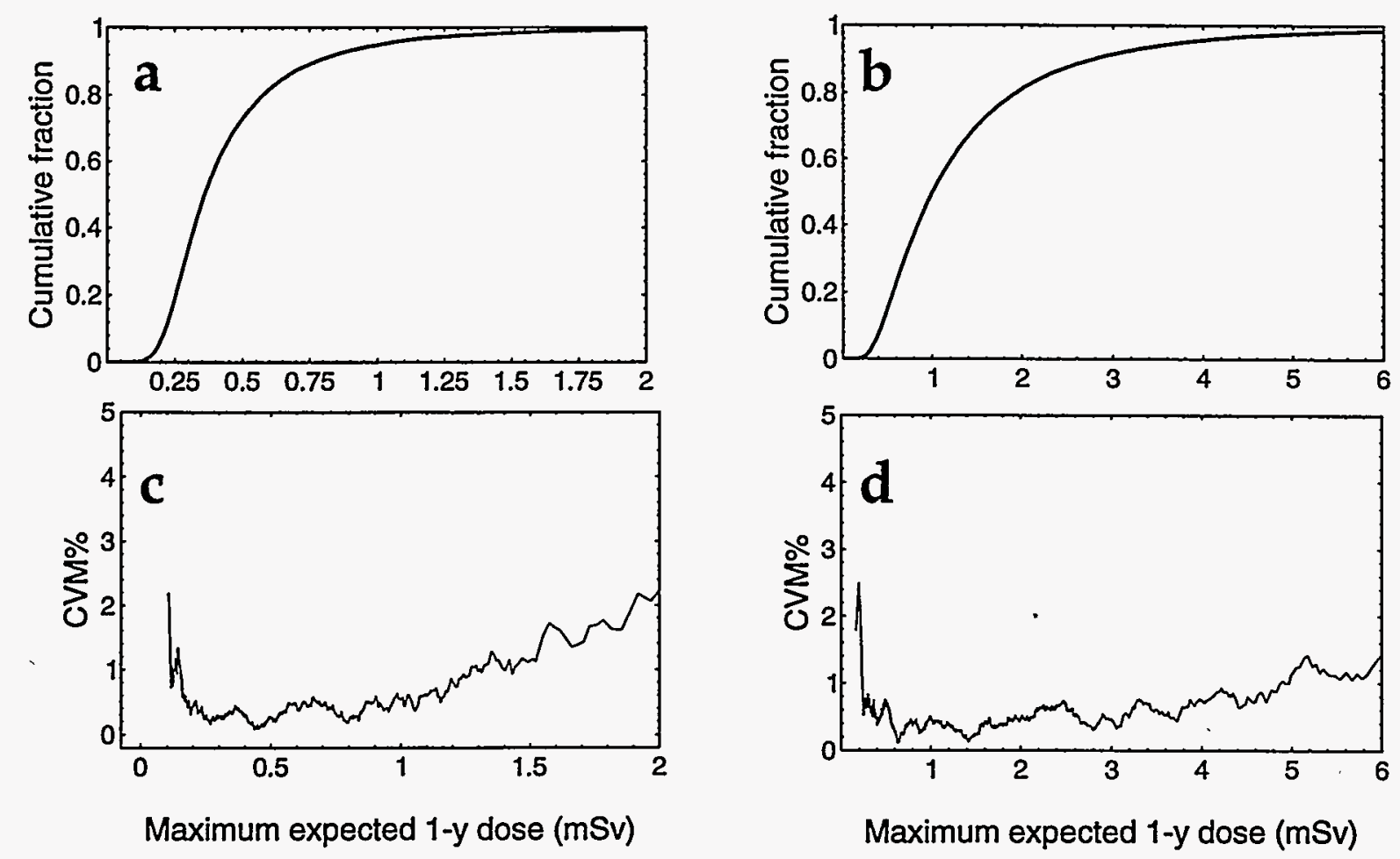

Figure 5.(a-b) Cumulative relative-frequency distributions for $\operatorname{Max}(\langle D(1)\rangle)$, characterizing interindividual variability in the maximum value of expected 1-y effective integral doses, regardless of which years each of these person-specific maxima happen to fall in. (c-d) Corresponding Monte-Carlo sampling errors (see Fig. 4). Plots pairs $(a, c)$ and $(b, d)$ correspond to imports-available and local-foodsonly diet assumptions, respectively.

each individual's predicted maximum 1-yr dose is primarily a function of the corresponding value of $H$ (the half-life for the dominant ${ }^{137} \mathrm{Cs}$ metabolic compartment). Note that the 99.5 th percentile values of $\operatorname{Max}(\langle D(1)\rangle)$ listed in Table 5 represent the maximum-likelihood values of dose to the corresponding persons receiving the maximum 1-y doses among all persons exposed under the IA and IUA diet assumptions, assuming an exposed population size of 200 (NRC, 1994; Bogen, 1995).

Figures 6a-d plot the population-average values of $\langle D(t)\rangle$ (expected effective integral dose as a function of time $t$ ) and their $95 \%$ confidence limits $(95 \% \mathrm{CL})$ with respect to interindividual variability for the imports-available and local-foods-only diets, both in absolute terms as well as values relative to the population-average at time $t$. Figures 6e-h plot the expected values of $\overline{D(t)}$ (population-average effective integral dose over time $t$ ) and their $95 \% \mathrm{CL}$ with respect to uncertainty for the 

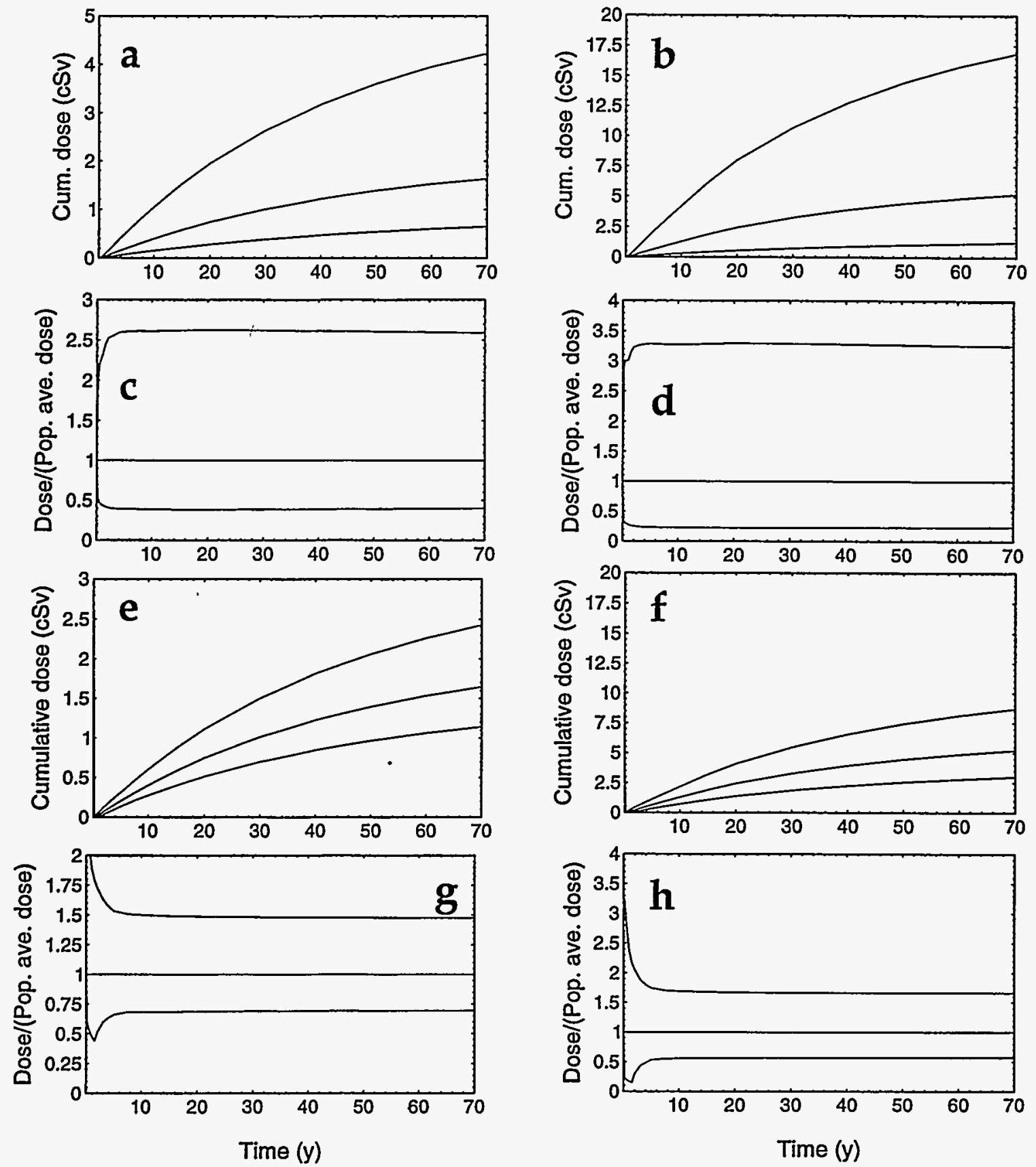

Figure 6. (a-b) Values of $\langle D(t)\rangle$ (expected effective integral dose over time $t$ ); in each plot: middle curve $=$ population-average value function, upper \& lower curves $=$ corresponding $95 \%$ confidence limits $(95 \% \mathrm{CL})$ with respect to interindividual variability. (e-f) Values of $\overline{D(t)}$ (population-average effective integral dose over time $t$ ); in each plot: middle curve = expected value function, upper \& lower curves = corresponding $95 \% C L$ with respect to uncertainty. $(c, d, g, h)$ Plots $a, b$, e and $f$ shown as values relative to the middle curve of each, respectively. Plots $\mathbf{a}, \mathbf{c}$, e and $\mathbf{g}$ correspond to an imports-available diet, and the other plots to a local-foods-only diet. 
imports-available and local-foods-only diets, both in absolute terms and as values relative to the expected value at time $t$.

Based on the hypothetical Bikini-remediation/resettlement scenario described above starting in 1999, population risk was estimated as described above from the characterizations of uncertainty in population-average lifetime dose $\overline{D(70)}$ obtained under the two different dietary ( $\mathrm{IA}=$ imports available, $\Pi \mathrm{UA}=$ imports unavailable) and two different population-size $(N=200, N=2000)$ assumptions considered. Each scenario implies a population-risk expectation, $\langle I\rangle$, and a corresponding probability of zero cases, $p_{0}=\operatorname{Prob}(I=0)$. Under the $\{\mathrm{IA}, N=200\}$ scenario, $\langle I\rangle \approx 0.20$ cases and $p_{0}=83 \%$; i.e., under this scenario it is rather more likely than not that zero cancer deaths will arise as a result of fallout-related exposures on Bikini. Under the $\{\mathrm{IA}, N$ $=2,000$ ) scenario, $\langle I\rangle \approx 0.86$ cases and a $p_{0}=43 \%$ (recall that under this scenario, 200 people are assumed to consume local foods within an IA diet, and the remaining 1,800 people are assumed to subsist entirely on imported foods). Under the (IUA, $N$ $=200\}$ scenario, $\langle I\rangle \approx 0.63$ cases and $p_{0}=58 \%$; i.e., even under this scenario it is more likely than not that zero cancer deaths will arise as a result of fallout-related exposures on Bikini. Under the \{IUA, $N=2,000\}$ scenario, $\langle I\rangle \approx 1.3$ cases and a $p_{0}=$ $30 \%$ (recall that under this scenario, 200 people are assumed to consume local foods within an IUA diet, and the remaining 1,800 people are assumed to subsist on imported foods).

\section{Discussion}

A detailed analysis of uncertainty and interindividual variability in estimated doses was conducted for a rehabilitation scenario for Bikini Island at Bikini Atoll, in which the top $40 \mathrm{~cm}$ of soil would be removed in the housing and village area, and the rest of the island is treated with potassium fertilizer, prior to an assumed resettlement date of 1999. Predicted doses were considered for the following falloutrelated exposure pathways: ingested Cesium-137 (137 Cs) and Strontium-90 (90Sr), external gamma exposure, and inhalation and ingestion of Americium-241 + Plutonium-239+240 ( $\mathrm{Am}+\mathrm{Pu}$ ). Two dietary scenarios were considered: (1) imported foods are available (IA), and (2) imported foods are unavailable (only local foods are consumed) (IUA). Corresponding calculations of uncertainty in estimated population-average dose showed that after $\sim 5 \mathrm{y}$ of residence on Bikini, the upper and lower $95 \%$ confidence limits with respect to uncertainty in this dose are estimated to be approximately 3 -fold higher and lower than its population-average 
value, respectively (under both IA and IUA assumptions). Corresponding calculations of interindividual variability in the expected value of dose with respect to uncertainty showed that after $\sim 5 \mathrm{y}$ of residence on Bikini, the upper and lower $95 \%$ confidence limits with respect to interindividual variability in this dose are estimated to be approximately 2-fold higher and lower than its expected value, respectively (under both IA and IUA assumptions). Assuming that 200 Bikini resettlers would be exposed to local foods (under both IA and IUA assumptions), the maximum 1-y dose received by any Bikini resident is most likely to be approximately 2 and $8 \mathrm{mSv}$ under the IA and IUA assumptions, respectively. Under the most likely dietary scenario, involving access to imported foods, this analysis indicates that it is most likely that no additional cancer fatalities (above those normally expected) would arise from the increased radiation exposures considered. 


\section{Appendix:}

Analytic and Monte-Carlo Methods Used to Characterize Uncertainty and Interindividual Variability in Estimated Doses to Hypothetical Bikini Residents

Define annual intake $R_{j}$ of ${ }^{137} \mathrm{Cs}$ in $\mathrm{Bq} \mathrm{kg}^{-1} \mathrm{y}^{-1}$ from local foods of type $j$ as $R_{j}=\sum_{i}^{n_{i}} \frac{365}{n_{j}} R_{i j}$ and corresponding total annual ${ }^{137} \mathrm{Cs}$ intake as $R=\sum_{j} R_{j}$. From Eqs. (1-3) and the notation, assumptions and definitions given in the text, integrated whole-body dose, $Q_{i j}\left(t-t_{i}\right)$ after $t$ years due to ingestion of ${ }^{137} \mathrm{Cs}$ in a food item of type $j$ at time $t_{i} \leq t$ is given by

$$
\begin{aligned}
Q_{i j}\left(t-t_{i}\right) & =\int_{t_{i}}^{t} c q_{i j}(u) d u \\
& =c F B R_{i j}\left\{\frac{e^{-\lambda t_{i}}\left(1-e^{-(\beta K+\lambda)\left(t-t_{i}\right)}\right)}{\beta K+\lambda}\right\} \\
& \equiv c F B R_{i j} S .
\end{aligned}
$$

For large $n_{j}$ and for $t_{i}$ distributed randomly throughout each year, it follows that total integrated whole-body dose $Q(t)$ in $\mathrm{Bq} \mathrm{kg}^{-1}$ after time $t$ (in y) may be approximated by

$$
F B\left\{c \sum^{t} R S\right\} \equiv F B X
$$

where $X$ is defined here as the braced quantity in definition (A3), for uniformly distributed $t_{i}$ between 0 and $t$. Thus, e.g., $\langle Q(t)\rangle=\langle X\rangle=\langle R\rangle\langle S\rangle$, where $\langle S\rangle$, the expectation of $S$ with respect to both $t_{i}$ and $\beta$, is given by

$$
\begin{aligned}
& \langle S\rangle=1+\frac{\Delta \beta+e^{-\lambda t}\left[\operatorname{Ei}\left(b_{1}\right)-\operatorname{Ei}\left(b_{0}\right)\right]-\operatorname{Ei}\left(c_{1}\right)+\operatorname{Ei}\left(c_{0}\right)+\operatorname{Ln}\left(c_{1} / c_{0}\right)}{\Delta \beta K \lambda t}, \\
& b_{i}=-\beta_{i} K t, \quad i=0,1, \\
& c_{i}=b_{i}-\lambda t, \quad i=0,1, \quad \text { and } \\
& \Delta \beta=\left(\beta_{1}-\beta_{0}\right)=(1.107-0.9)=0.207
\end{aligned}
$$


in which $\operatorname{Ei}(z)$ is the exponential integral $\int_{-z}^{\infty} x^{-1} e^{-x} d x$. The (unsubscripted) constant $c$ was estimated to be $2.419 \times 10^{-4} \mathrm{cSv} \mathrm{kg} \mathrm{Bq}^{-1} \mathrm{y}^{-1}$ from values of cumulative wholebody-equivalent ${ }^{137} \mathrm{Cs}$ dose for adults predicted from the equivalent ICRP (1990) model (Figure A1).

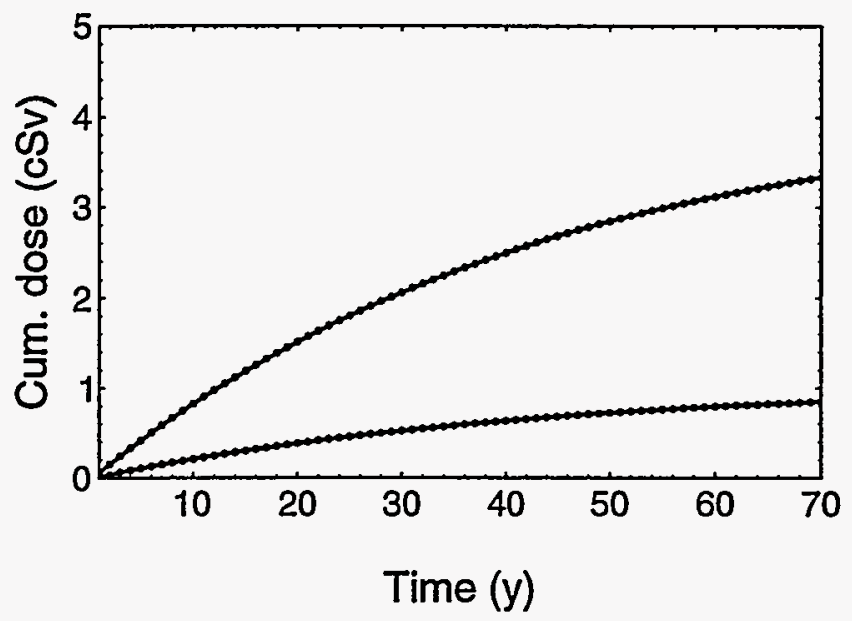

Figure A1. Expected population-average adult $137 \mathrm{Cs}$ dose, $\overline{\langle X\rangle}$, to potential Bikini Island residents as a function of post-resettlement time starting in 1999, after site remediation measures and under dietary assumptions described by Robison et al. (1995). Points shown were predicted using the ICRP (1990) adults-only model for 137Cs; curves shown are predicted by Eqs. (A3-A4), conditional on populationaverage values for $\langle R\rangle$ and $K$, and on a fitted value of $2.419 \times 10^{-4} \mathrm{cSv} \mathrm{kg} \mathrm{Bq} \mathrm{Bg}^{-1}$ for the constant $c$. Lower (upper) curve and associated points correspond to the assumption that imported foods will be available (unavailable).

From Eqs. (A3-A4) and corresponding assumptions discussed in the text, interindividual variability in expected dose $\langle D(t)\rangle$ by time $t$ was characterized by evaluating

$$
\langle D(t)\rangle=D_{\mathrm{AmPu}}(t)+X_{\gamma} \overline{D_{\mathrm{x}}(t)}+\langle B\rangle\left[\langle F\rangle\langle X\rangle+G\left(\frac{\langle X\rangle / F}{\overline{\langle X\rangle / \bar{F}}}\right) W(t) D_{\mathrm{Sr}}(t)\right]
$$

Variability in $\langle D(t)\rangle$ thus arises from uniform variability in $F$ and $G$ (taken to be $100 \%$ rank-correlated-see text), and from lognormal variability in both $\langle R\rangle$ and $H$ (see text). 
Uncertainty in population-average dose $\overline{D(t)}$ was characterized by evaluating

$$
\overline{D(t)}=D_{\mathrm{AmPu}}(t)+\overline{X_{\gamma}} \overline{D_{x}(t)}+B \bar{F}\left[\bar{X}+\bar{G}\left(\frac{\bar{X}^{*}}{\langle\bar{F}\rangle}\right) W(t) D_{\mathrm{Sr}}(t)\right],
$$

in which the subscript asterisk denotes an independent random sample from the subscripted variate (for reasons discussed in the text). Uncertainty in Eq. (A6) arises in part from the uniform and lognormal uncertainties assumed for $\bar{F}$ and $B$, respectively (see text), in addition to uncertainty is associated with the variate $\bar{X}$ arising from $X$ defined in Eq. (A3). Let the subscript $p$ on a variate denote a variate value pertaining to a particular individual in the exposed population. Thus, $X_{p}$ $=X \mid\left\{R=R_{p}, H=H_{p}\right\}$ and $\left(X_{p} \mid \beta\right)$ is the sum of a presumed large number of identical independently distributed random variates. From the Lindeberg and Central Limit theorems, it follows that $\left(X_{\mathrm{p}} \mid \beta\right)$ is approximately normally distributed with mean and variance given by

$$
\begin{aligned}
\left\langle X_{\mathrm{p}} \mid \beta\right\rangle & =c t\left\langle R_{\mathrm{p}}\right\rangle\left\langle S_{\mathrm{p}} \mid \beta\right\rangle \text { and } \\
\sigma_{X_{\mathrm{p}} \mid \beta}^{2} & =c^{2} t\left\langle R_{\mathrm{p}}\right\rangle^{2}\left[\left(1+\gamma_{R}^{2}\right)\left\langle S_{\mathrm{p}}^{2} \mid \beta\right\rangle-\left\langle S_{\mathrm{p}} \mid \beta\right\rangle^{2}\right],
\end{aligned}
$$

respectively, in which

$$
\gamma_{R}=\overline{\langle R\rangle^{-1}}\left(\sum_{j=1}^{11}\left\langle R_{j}\right\rangle^{2} \gamma_{R_{i j}}^{2} n_{j}^{-1}\right)^{1 / 2}=0.039
$$

is the $\mathrm{CV}$ for uncertainty in any individual's modeled lifetime, time-weighted average ${ }^{137} \mathrm{Cs}$ intake, based on the assumptions stated in the text and the food-typespecific $C V$ values listed in Table 3. Assuming the exposed population size is sufficiently large to ensure that differences between first and second sample moments with respect to variability and their corresponding population moments are negligible, it follows from the definition of variability expectation that uncertainty in $\overline{X \mid \beta}$ is approximately normally distributed with mean and variance given by 


$$
\begin{aligned}
\overline{\langle X \mid \beta\rangle} & =\frac{1}{N} \sum_{\mathrm{p}=1}^{N}\left\langle X_{\mathrm{p}} \mid \beta\right\rangle \approx c t \overline{\langle R\rangle \overline{\langle S \mid \beta\rangle} \text { and }} \\
\sigma_{\overline{\mathrm{X} \mid \beta}}^{2} & =\frac{1}{N^{2}} \sum_{\mathrm{p}=1}^{N} \sigma_{X_{\mathrm{p}} \mid \beta}^{2} \\
& \approx c^{2} \overline{t\langle R\rangle^{2}}\left(1+g_{R}^{2}\right)\left[\left(1+\gamma_{R}^{2}\right) \overline{\left\langle S^{2} \mid \beta\right\rangle}-\overline{\langle S \mid \beta\rangle}^{2}\right],
\end{aligned}
$$

respectively, where

$$
\begin{aligned}
\langle S \mid \beta\rangle= & {[(\beta K+\lambda) t]^{-1}\left[\left(1-e^{-\lambda t}\right) \lambda^{-1}-\left(e^{-(\beta K+\lambda) t}-e^{-\lambda t}\right)(\beta K)^{-1}\right], \quad \text { and } } \\
\left\langle S^{2} \mid \beta\right\rangle= & (\beta K+\lambda)^{-2} t^{-1}\left\{(2 \lambda)^{-1}+e^{-\lambda t}\left[\left(1-2 e^{-\beta K t}\right)(2 \beta K t)^{-1}+\right.\right. \\
& \left.\left.2\left(e^{-(\beta K-\lambda) t}-1\right)(\beta K-\lambda)^{-1}-(2 \lambda)^{-1}\right]\right\} .
\end{aligned}
$$

The averages $\overline{\langle S \mid \beta\rangle}$ and $\overline{\left\langle S^{2} \mid \beta\right\rangle}$ with respect to $H$ were each evaluated numerically for different $\beta$ values equally spaced over the range of $\beta$, whereupon it is evident that $\sigma_{\overline{X \mid \beta}} t^{-1 / 2}$ is for each given $t, 0<t \leq 70 \mathrm{y}$, a virtually linear function of $\overline{\langle X \mid \beta\rangle} t^{-1}$ over a $\beta$-and $t$-dependent range of the latter (see Figure A2). It is also evident that corresponding $\overline{\langle X \mid \beta\rangle} t^{-1}$ values are virtually uniformly distributed over these linear ranges (Figure A2). The linear coefficients $\{a, b \mid t\}$ and corresponding $\overline{\langle X \mid \beta\rangle} t^{-1}$-range boundaries $\left\{x_{10}, x_{\mathrm{hi}} \mid t\right\}$ were therefore determined for representative values of $t$, and this information was then used to evaluate uncertainty in $\bar{X}$, for $\bar{X}$ modeled as a compound normal distribution with mean $=U t$ and $\mathrm{SD}=t^{1 / 2}(a+b U)$, where $U$ is uniformly distributed between $x_{\mathrm{lo}}$ and $x_{\mathrm{hi}}$.

Except where the use of $100 \%$ rank-correlated variates was indicated, all variate simulations were conducted using 10 sets of virtually uncorrelated vectors of 2,000 values for each variate involved, generated using systematic Latin-Hypercube sampling procedures. Each $i$ th output fractile (and the first moment) was estimated as the mean of 10 th ordered values (and first moments) of the 10 corresponding sets of 2000 evaluations of Eq. (A5) or (A6), for $i=1,2, \ldots, 2000$. Corresponding MonteCarlo sampling errors, defined for each estimate as the coefficient of variation of the mean (CVM, equal to the standard error of the mean divided by the mean). Calculations were done on a NeXT workstation using the programs Mathematica 
2.2.2 (Wolfram, 1991) and RiskQ (Bogen, 1992). Analyses of quantile convergence indicate that fractile estimates obtained are generally accurate to within $<2 \%$ (see Figures 4 and 5), and that mean values obtained are accurate to within $<0.2 \%$.
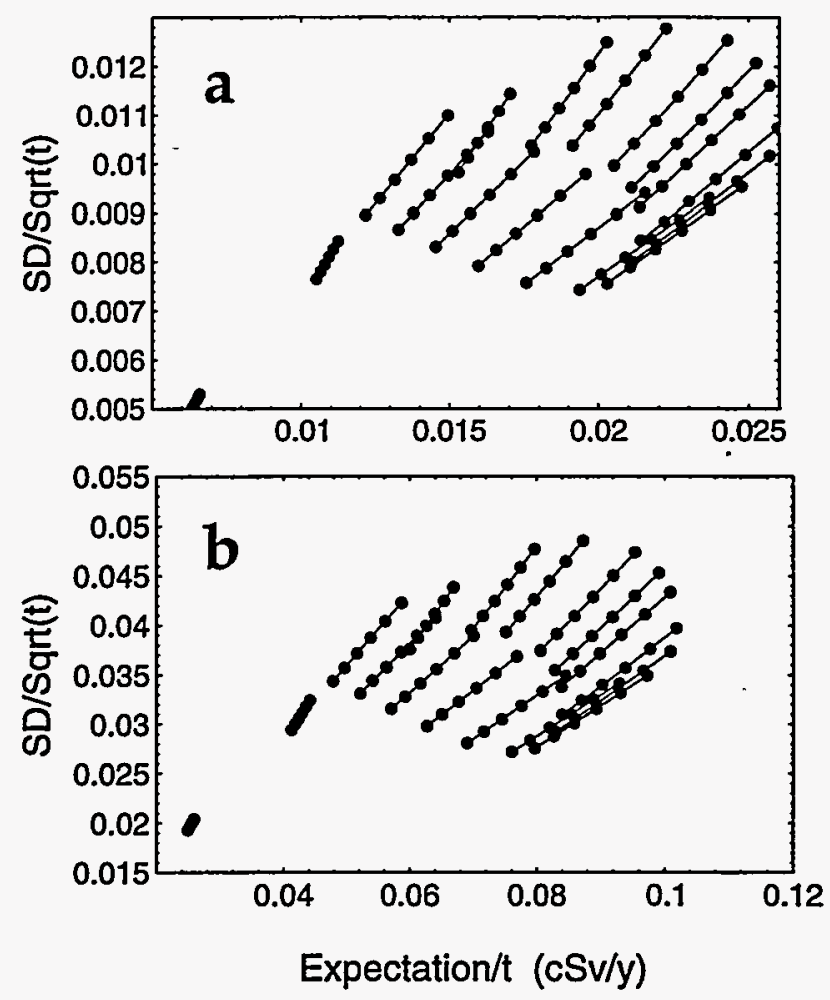

Figure A2. The standard deviation (SD), denoted $\sigma_{\overline{X_{10}}}$ in Eq. (A9), as a function of the corresponding expected value (Expectation), denoted $\langle\mathrm{X} \mid \beta\rangle$ in Eq. (A8), where these quantities are normalized by $t^{1 / 2}$ and by $t$, respectively, evaluated for 17 values of time $t$ ranging from 0.25 to $70 \mathrm{y}$ (corresponding to 17 sets of approximately linearly connected points shown) and five equally spaced values of $\beta$, in the range 0.9 to 1.107, corresponding to each set of six connected points shown. 


\section{References}

Aitchison, J., and J.A.C. Brown, (1957), The Lognormal Distribution, Cambridge U. Press, New York.

Bennett, B.C. (1973), Strontium-90 in Human Bone, 1972 Results from New York City and San Francisco, United States Atomic Energy Commission Health and Safety Laboratory, New York, NY, HASL-274.

Bennett, B.C. (1977), Strontium-90 in Human Bone, 1976 Results from New York City and San Francisco, United States Atomic Energy Commission Health and Safety Laboratory, New York, NY, HASL-328.

Bennett, B.C. (1978), Strontium-90 in Human Bone, 1977 Results from New York City and San Francisco, United States Atomic Energy Commission Health and Safety Laboratory, New York, NY, HASL-344.

Bogen, K.T., and R.C. Spear (1987), "Integrating Uncertainty and Interindividual Variability in Environmental Risk Assessment," Risk Analysis 7, 427-436.

Bogen, K.T. (1990), Uncertainty in Environmental Health Risk Assessment. Garland Publishing Co., New York.

Bogen, Kenneth T. (1992), RiskQ: An Interactive Approach to Probability, Uncertainty, and Statistics for Use with Mathematica, Reference Manual, Lawrence Livermore National Laboratory, Livermore, CA, UCRL-MA-110232.

Bogen, K.T. (1995), "Methods to Approximate Joint Uncertainty and Variability in Risk," Risk Analysis 15, 411-419.

Cristy, M.R., W. Leggett, D.E. Dunning, Jr., and K.F. Eckerman (1984), AgeDependent Dose-Conversion Factors for Selected Bone-Seeking Radionuclides, Nuclear Regulatory Commission, NUREG/CR-3535, ORNL/TM-8929.

Cristy, M., and K.F. Eckerman (1987a), Specific Absorbed Fractions of Energy at Various Ages from Internal Photon Sources. I Methods, Oak Ridge National Laboratory, Oak Ridge, TN, ORNL/TM-8381/V1.

Cristy, M., and K.F. Eckerman (1987b), Specific Absorbed Fractions of Energy at Various Ages from Internal Photon Sources. II. One-Year-Old, Oak Ridge National Laboratory, Oak Ridge, TN, ORNL/TM-8381/V3.

International Atomic Energy Agency (IAEA) (1989), Evaluating the Reliability of Predictions Made Using Environmental Transfer Models, Safety Series 100. IAEA, Vienna.

International Commission on Radiological Protection (1988), Limits for Intakes of Radionuclides by Workers: An Addendum, Pergamon Press, New York, Pub. 30, Part 4. 
International Commission on Radiological Protection (1990), Age-Dependent Doses to Members of the Public from Intake of Radionuclides: Part 1, Pergamon Press, New York, Pub. 56.

International Commission on Radiological Protection (1991), 1990 Recommendations of the International Commission on Radiological Protection, Pergamon Press, New York, Pub. 60.

Klusek, C.S. (1979), Strontium-90 in Human Bone-1987 Results for New York City and San Francisco, U.S. Department of Energy, Environmental Measurements Laboratory, New York, EML 363.

Leggett, R.W., K.F. Eckerman, and L.R. Williams (1982), "Strontium-90 in Bone: A Case Study in Age-Dependent Dosimetric Modeling," Health Phys. 43, 307-322.

National Research Council (NRC) (1990), Health Effects of Exposure to Low Levels of Ionizing Radiation (BEIR V), NRC Committee on the Biological Effects of Ionizing Radiations (BEIR), Board on Radiation Effects Research, Commission on Life Sciences. National Academy Press, Washington, DC.

National Research Council (NRC) (1994), Science and Judgment in Risk Assessment, NRC Committee on Risk Assessment of Hazardous Air Pollutants, Board on Toxicology, Commission on Life Sciences. National Academy Press, Washington, DC.

Nazaroff, W.W., S.M. Doyle, A.V. Nero, and R.G. Sextro (1987), "Potable Water as a source of airborne ${ }^{222 \mathrm{Rn}}$ in U.S. Dwellings: A Review and Assessment," Health Phys. 52, 281-295.

Papworth, D.G., and J. Vennart (1973), "Retention of 90Sr in Human Bone at Different Ages and the Resulting Radiation Doses," Phys. Med. Biol. 18, 168.

Papworth, D.G., and J. Vennart (1984), "The Uptake and Turnover of $90 \mathrm{Sr}$ in the Human Skeleton," Phys. Med. Biol. 29, 1045-1061.

Pearson, E.S., and H.O. Hartley (1972), Biometrika Tables for Statisticians, Vol. 2, Cambridge University Press, London, pp. 117-119, 146, 359.

Rivera, J. (1967), "Predicting Strontium-90 Concentrations in Human Bones," in Strontium Metabolism, J.M.A. Lenihan, J.F. Louitt, and J.H. Martin, Eds., (Academic Press, New York), pp. 47-55.

Robison, W.L., C.L. Conrado, and M.L. Stuart (1988), Radiological Conditions at Bikini Atoll: Radionuclide Concentrations in Vegetation, Soil, Animals, Cistern Water, and Ground Water, Lawrence Livermore National Laboratory, Livermore, CA, ÚCRL-53840.

Robison, W.L., C.L. Conrado, and K.T. Bogen (1994a), An Updated Dose Assessment for Rongelap Island, Lawrence Livermore National Laboratory, Livermore, CA, UCRL-LR-107036. 
Robison, W.L., K.T. Bogen, C.L. Conrado (1994b), "A Dose Assessment for a U.S. Nuclear Test Site-Bikini Atoll," in: Assessing the Radiological Impact of Past Nuclear Activities and Events, IAEA-TECDOC-755, International Atomic Energy Agency (IAEA), Vienna, Austria, pp. 11-24.

Robison, W.L., K.T. Bogen, and C.L. Conrado (1995), An Updated Dose Assessment for a U.S. nuclear Test Site-Bikini Atoll, Lawrence Livermore National Laboratory, Livermore, CA, UCRL-ID-122368.

Schwartz, G., and D.E. Dunning, Jr. (1982), "Imprecision in Estimates of Dose from Ingested $137 \mathrm{Cs}$ due to Availability in Human Biological Characteristics," Health Physics 43, 631-645.

Stephens, M.A. (1970), "Use of the Kolmolgorov-Smirnov, Cramer-von-Mises and Related Statistics without Extensive Tables," J. Royal Stat. Soc. Ser. B 32(1), 155122.

Wolfram, Stephen (1991), Mathematica: A System for Doing Mathematics by Computer, 2nd. ed. Addison-Wesley Publishing Company, Inc., Reading, MA. 


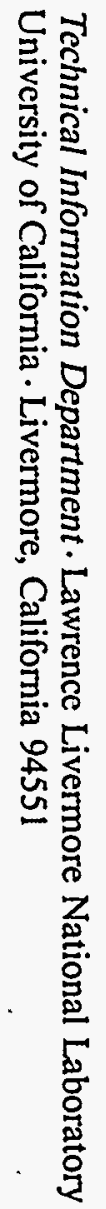

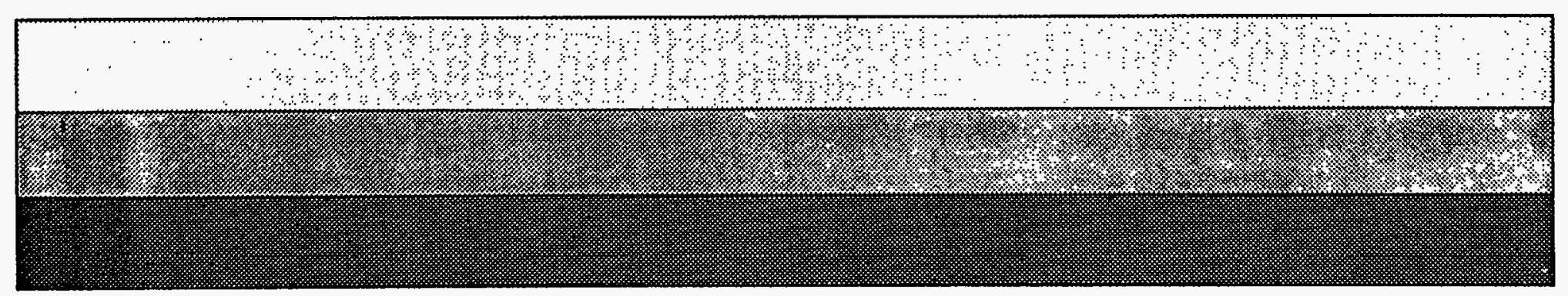

